\title{
Creative Achievement and Individual Differences: \\ Associations Across and Within the Domains of Creativity
}

\author{
Darya L. Zabelina \\ University of Arkansas \\ Elina Zaonegina \\ William Revelle \\ Northwestern University \\ David M. Condon \\ University of Oregon
}

Author Note

This research was supported in part by grant SMA-1419324 from the National Science Foundation to William Revelle and David M. Condon and by grant RFP-15-04 from the Imagination Institute to David M. Condon and Darya L. Zabelina.

Correspondence concerning this article should be addressed to David M. Condon at dcondon@uoregon.edu. University of Oregon, 1227 University Street, Eugene, OR 97403. 


\begin{abstract}
We investigated the relationships between creative achievement, cognitive ability, temperament, and vocational interests using a large and diverse internet-based sample. Ten creative domains (visual arts, music, creative writing, dance, drama, architecture, humor, scientific discovery, inventions, culinary arts) were positively associated with higher cognitive ability, intellect and extraversion, and lower agreeableness. With regard to cognitive ability, there was no evidence for the threshold effect on achievements. With regard to age, younger individuals endorsed a greater number of low-level achievements and older individuals more high-level achievements across the 10 creative domains. Other characteristics of individual differences (e.g., vocational interests) were more domain-specific for predicting creative achievement. We also introduce a revised method for the assessment and scoring of creative achievements, and discuss suggestions for future research.
\end{abstract}

Keywords: creative achievement, cognitive ability, Big Five, vocational interests, Threshold Hypothesis 
Creative Achievement and Individual Differences:

\section{Associations Across and Within the Domains of Creativity}

Identifying "creative" individuals has proven to be a fundamental challenge in creativity research. In part, this challenge reflects the difficulty of identifying universal criteria for creativity. This is not an insurmountable concern, in and of itself, but it leads to the related difficulty of evaluating creativity in a manner that accounts for the diversity of ways and circumstances in which it may be expressed. In other words, the difficulty of defining creativity makes it particularly difficult to compare creative expression across domains and differing levels of expertise.

These difficulties are mirrored by the task of assessing personality and individual differences. After more than a century of effort, psychological assessment still lacks an integrated framework for evaluating the myriad ways that people think, feel, and behave differently (Ackerman, 2004; Condon, 2014), even though substantial progress has been made for the assessment of subsets of these differences. The Big Five (Goldberg, 1993), for example, to assess personality, the Cattell-Horn-Carroll model of cognitive abilities (McGrew, 2009), and the RIASEC (Armstrong et al., 2008) and ORVIS (Pozzebon et al., 2010) models of vocational interests.

The present work is motivated by the search for a better understanding of the relations between advanced levels of creative expression (i.e., creative achievements) and the psychological individual differences broadly defined. Previous work has not sought to evaluate the relations across both broad lines of inquiry, but this step is seen as a prerequisite to the eventual development of a measurement framework that can claim to be both comprehensive and compact, sensitive and specific. As such, our aim was to evaluate these associations using a 
comprehensive assessment of creative achievement (across 10 different domains) alongside several frameworks for assessing psychological individual differences using a large international sample collected online.

\section{Measuring Manifest Creativity}

The creativity criterion problem seems to fit the famous words of Justice Potter Stewart in reference to obscenity: "I know it when I see it" (Jacobellis v. Ohio; 378 US 184 [1964]). Despite the challenge of describing creativity in a way that works well across domains, it has been broadly defined as thought or behavior that is both novel and useful (Simonton, 1988; Sternberg \& Lubart, 1999). This definition is vague enough to fit across a variety of situations, including evaluations of (i) the perceived creativity of a scholarly or artistic work relative to the standards normally expected of someone who is like the creator of such works, (ii) the extent to which such works are comparable to similar extant works or standards in an absolute sense, and (iii) the extent to which such works are perceived as useful for the context in which they are produced. Consider, for example, the different standards of creativity among children and adults, among the sciences and the arts, and even among more established and less developed subdisciplines.

Given this complexity, a consequence of the difficulty in defining creativity has been the difficulty in measuring it. Comprehensive assessment requires the specification of characteristics of creative output that work both within and between creative domains, and across differing levels of expertise. Despite the challenges, several approaches have been developed. These include the assessment of creative products, creative cognition, creative traits, and creative behavior and accomplishments (Kaufman et al., 2009; Silvia et al., 2012). Psychologists conducting lab-based research have primarily used performance based measures such as those 
for divergent thinking, where participants are asked to generate ideas in response to verbal or figural prompts (Guilford, 1959; Torrance, 1974). One example of such a task asks participants to describe unusual uses for common objects like a brick, from which scores of fluency (number of responses) and originality (novelty or originality of ideas compared to the norm) can be derived. However, meta-analyses of the divergent thinking literature suggest that these measures may have poor internal consistency and low predictive validity of future creative behaviors (Baer \& Kaufman, 2005; Plucker, 2004, 2005; Silvia et al., 2008; but see Torrance, 1988).

Several self-report measures have also been employed to assess creativity. One example is the Creative Domain Questionnaire (CDQ; Kaufman et al., 2009), which asks participants to rate whether they believe they have talent across several domains using a Likert-type scale. A revised version, the CDQ-R, includes 21 items that produce four factor scores (drama, math/science, arts, and interaction), with each item's response ranging from "Not at all creative" to "Extremely creative" (Kaufman et al., 2009). However, the framing of measures like the CDQ has been critiqued on the grounds that participants may not be aware of the extent to which their creativity in a given domain relates to others, and this concern is exacerbated by the tendency for socially desirable responding (Kaufman et al., 2015; Silvia et al., 2009).

Another approach is to measure specific creative behaviors and achievements across multiple domains of potential expression. The Creative Behavior Inventory (CBI; Hocevar, 1980) has been widely used in creativity research because its 90 items reflect everyday creative behavior in the domains of fine arts, crafts, literature, math-science, performing arts, and music (Silvia et al., 2012). The items were generated using college students' lists of their most creative achievements and behaviors and then selecting those that experts in the field deemed as creative. While the inventory is advantageous in that it asks participants to note how many times they 
accomplished various creative behaviors, scores are based on only four domains and do not reflect differences in the difficulty among behaviors (Hocevar, 1979). Moreover, because the inventory of items was generated from a college-aged sample, it does not assess higher-order achievements and therefore fails to differentiate among high levels of expression.

The Creative Achievement Questionnaire (CAQ) was designed to address the shortcomings of previous measures through the self-report assessment of real-life creative achievements of variable difficulty across multiple domains (Carson et al., 2005). The CAQ improves on previous measures by 1) separating achievement domains while still allowing for a summed achievement score across domains, 2) accounting for training in a given domain, and 3) giving more weight to achievements that are locally or nationally recognized by field experts (Carson et al., 2005). It also reduces self-report bias somewhat in that participants only respond to whether or not they have completed a given achievement rather than asking them to evaluate their own creativity more holistically. While this does not preclude the possibility of overstatement about one's achievements, it is presumed to reduce the incidence of incidental or unintentional response bias.

With some exceptions (e.g., Kaufman et al., 2016), prior research based on the CAQ has generally used samples of limited size and demographic representation, with participants recruited from university populations. This is especially problematic given that respondents from these populations are relatively more homogenous than the general population ( Rad et al., 2018), and they are, by definition, still involved in educational training. In other words, their opportunities to express creativity across multiple domains may have been limited. Moreover, given that creative achievements tend to be characterized by a non-Gaussian, reverse "J" distribution, small sample sizes are unlikely to provide an accurate representation of the larger 
population. In other words, creative achievement has a low base-rate and is positively skewed (Silvia et al., 2012).

The research described here is based on large-scale assessment of creative achievements in an online sample that is relatively more diverse with respect to age, race, and educational attainment than is typically reported by studies using convenience samples. The measurement of creative achievement was based on a revision of the CAQ that attempted to address issues relating to positive skewing and the unequal weighting of creative achievements within a given domain. Before describing our hypotheses for the study herein, we briefly review previous findings that relate creativity and creative achievement to psychological individual differences.

\section{Creativity and Personality}

Among the "Big Five" personality traits (Digman, 1990, Goldberg, 1990), the link between Openness/Intellect and creativity is the most robust finding (Kaufman et al., 2015; King et al., 1996; McCrae, 1987; Nusbaum \& Silvia, 2011; Silvia et al., 2009). This positive relationship is unsurprising given that creative people tend to be intellectually curious, imaginative, open-minded, and aesthetically sensitive (Nusbaum \& Silvia, 2011), as all of these traits are expressed by people who score highly in openness to experience. Many researchers further specify this factor as being comprised of the distinct, but correlated sub-traits of Openness to Experience (Trapnell, 1994; DeYoung et al., 2014) - reflecting cognitive engagement with perception, fantasy, aesthetics, and emotions (Kaufman et al., 2015) and Intellect, reflecting cognitive engagement with abstract and semantic information, primarily through reasoning (Kaufman et al., 2015). Differentiation between these aspects may well be relevant, as preliminary evidence suggests that Openness predicts creative achievement in the arts and Intellect predicts creative achievement in the sciences (Kaufman et al., 2015). 
Low agreeableness is also generally associated with creative achievement. For instance, young adults who score highly in agreeableness have fewer creative achievements in both genders (King et al., 1996). Similarly, within the scientific community (e.g., physicists, chemists, and biologists), low agreeableness predicts creative eminence (Feist, 1993), and artists score lower on agreeableness measures than non-artists (Burch et al., 2006). A meta-analysis revealed that low agreeableness predicts more creative achievements among both scientists and artists (Feist, 1998). The six-factor HEXACO model of personality, which splits the agreeableness factor into honesty-humility and agreeableness, provides further insight into traits that predict creativity. Honesty-humility - comprised of the facets of sincerity, fairness, greed-avoidance, and modesty - has been found to be inversely related with creativity, though there is no relationship between creativity and agreeableness in the Big Five framework (Silvia et al., 2011).

Some small to medium effects have been found for the relationship between creative achievement and extraversion (Silvia et al., 2011). Kaufman et al. (2015) found that extraversion predicts creative achievement in the arts, but not the sciences. However, for the remaining Big Five personality traits (Emotional Stability and Conscientiousness), essentially no meaningful relationships have been found with creative achievements (Batey \& Furnham, 2006; Furnham \& Bachtiar, 2008; Silvia et al., 2011).

\section{Creativity and Intelligence}

The relationship between creativity and intelligence is a topic of some dispute. The nature of the relationship has been framed from several perspectives: (1) that creativity and intelligence are entirely separate constructs, (2) independent but overlapping, (3) subsets of each other (in either direction), and (4) as coextensive sets (Jauk et al., 2013). Among these models, creativity is most often regarded as a lower order factor of intelligence (Jauk et al., 2013), suggesting that 
creativity overlaps with some other features of intelligence and is itself a cognitive ability. A consistent substantive question in the joint study of creativity and intelligence has been the threshold hypothesis, which posits that there is some threshold of intelligence beyond which the positive association with creativity no longer holds (Guilford, 1967). The implication of this hypothesis is that other psychological individual differences (e.g., personality or interests) become relatively more informative when differentiating between individuals of high cognitive ability (Guilford, 1967). Recent studies have failed to find support for the threshold hypothesis. A study of adolescents, for example, who scored in the top $1 \%$ of quantitative reasoning ability found that higher levels of cognitive ability remained predictive of more achievements, including patents, peer-reviewed publications, and doctorates (Robertson et al., 2010). Similarly, Jauk and colleagues (2013) did not find evidence for the threshold hypothesis in a separate study of creative achievement among the highly intelligent, although they did report a threshold for divergent thinking.

\section{Creativity and Vocational Interests}

Some training or cultivation of one's interests is often a prerequisite for creative achievement, and this is cleverly introduced into the measurement of creative achievement in the CAQ (Carson et al., 2005). However, creative individuals often surpass introductory training by dedicating their lives to broadening and/or deepening their creative passions. This frequently follows a developmental trajectory that is well-described by Savi and colleages (2019), beginning as a passing or circumstantial interest before becoming incorporated into one's identity and eventually unfolding into a lifelong professional pursuit. There is considerable evidence to support this trajectory, such as findings that adult creative achievement is positively correlated with a consistent future career image beginning in elementary school (Torrance, 1987), that more 
than $75 \%$ of Westinghouse Science Competition finalists earned doctoral degrees and stayed within science or medicine for their careers (Feist, 2006), and that members of the National Academy of Science who recognized their own scientific interests at an earlier age had more lifetime scientific achievements (Feist, 2006). Of course, this is not the only path to creative achievement as many people pursue careers that are unrelated to their college major, and even change paths frequently throughout their careers. Since few studies have previously examined the relationship between creative achievement and vocational interests while also considering other features of personality and cognitive ability, it remains an open question whether interests can explain a substantial proportion of the variability in creative achievement.

\section{Creativity and Age}

In the case of scientific creativity, findings have converged on the conclusion that there is an inverted-U relationship between age and productivity (Lehman, 1953; Simonton, 1988; Zuckerman, 1996), with peaks varying across disciplines - earlier in math and physics and later in biology and geology (Simonton, 1988). It has been suggested that the decline in creative contributions in later ages may be due to decreased preference for complexity and lower divergent thinking performance rather than a decrement in intelligence (Alpaugh \& Birren, 1977). Despite this evidence for variable rates of creative achievement across the lifespan, the number of lifetime creative achievements should be greatest for older individuals. To our knowledge, there have not been studies to verify this, likely due to the aforementioned problem of largely undergraduate sampling.

\section{Goals of the Current Studies}

Using a large and diverse sample of individuals, the study described below aimed to examine the relationships between creative achievement and personality, interests, cognitive 
ability, and age. Because the participants in this sample represented a self-selected sub-sample of a large internet-based personality assessment (www.SAPA-project.org), the first analysis compared the respondents to those that did not choose to participate. We hypothesized that participants would score more highly on traits that are associated with creativity because individuals should be more likely to complete a creativity questionnaire if they believe they are more creatively inclined. Specifically, we expected higher scores in Openness/Intellect, general cognitive ability, and most interest domains.

The second analysis evaluated the nature of the relationship between creativity and cognitive ability. While we anticipated a positive relationship, we also sought to consider the evidence for the threshold hypothesis (Guilford, 1967) by testing to see whether this relationship remained positive at the higher ends of cognitive ability. Based on recent prior research, we did not expect to find strong support for the threshold hypothesis. Third, we sought to evaluate the shape of the relationship between creative achievement and age in order to determine whether older participants are more likely to have a greater number of creative achievements. We predicted that this was highly likely to be the case given that the development of expertise - and, in fact, the pursuit of achievements - requires time and training.

Finally, we sought to evaluate the primary correlates of creative achievement. In particular, we aimed to identify the differential predictive validity of individual differences across the various domains of creative achievement. While prior research has independently explored the relationships between creative achievement and personality (McCrae, 1987; Nusbaum \& Silvia, 2011), creative achievement and college major (Feist, 2006), and creative achievement and intelligence (Jauk et al., 2013; Robertson et al., 2013), we aimed to provide a more informed understanding of how personality, vocational interests, and cognitive ability 
together account for variance in creative achievements. It was hypothesized that each of these individual differences domains would be variably predictive of creative achievement by domain, but we had no a priori hypotheses about the relative variance explained by each (personality vs interests vs cognitive ability).

\section{Method}

\section{Participants}

Of the 63,486 (58\% female) individuals who responded to the personality inventory at SAPA-Project.org between May 20, 2013 and June 10, 2014 in exchange for customized feedback about their personalities, 3,841 (62.2\% female) of these individuals completed the optional Creative Achievement Questionnaire (CAQ; Carson et al., 2005, described below and included as an Appendix) after the main personality inventory. The mean self-reported age of CAQ respondents was 28.2 years $(s d=11.9$; median $=24)$ with a range from 14 to 82 years (compared to the SAPA sample: $M=25.6, s d=10.3$, median $=22$ ). Educational attainment levels for both sets of participants are given in Table 1; CAQ respondents were more highly educated than non-respondents as indicated by the higher proportions of respondents with college/university and graduate/professional degrees. Race/ethnicity is presented for the U.S. participants (58\% of the total) in Table 2; White/Caucasian participants represented a larger proportion of the respondent sample than the rest of the SAPA sample.

Some participant data were excluded due to inconsistent or uninterpretable responses. This mainly occurred for participants who skipped all questions for one or more domains including the item that asked them to indicate if they did not have any recognized achievements in that area. Only participants who provided a response for all ten domains were included in the analyses. Additional participant data were discarded if participants provided uncommon 
responses to certain demographic questions, such as an age younger than 14 or older than 90 years.

\section{[INSERT TABLE 1]}

\section{[INSERT TABLE 2]}

\section{Measures}

All data were self-reported and were administered using the Synthetic Aperture Personality Assessment (SAPA) technique (Revelle et al., 2016; Wilt et al., 2012), a variant of matrix sampling procedures discussed by Lord (1955). Consistent with these procedures, participants were administered random samples of large sets of the personality, cognitive ability and interest items described below. Exclusive of questions regarding creative achievement and participant characteristics (i.e., gender, age, country of origin, and education), each participant responded to a mean of 96 items from these domains (median $=88, s d=48.9)$; variability in the total number was independent of participant characteristics. This technique allows for the generation of synthetic correlations across the full range of measured constructs even though a reasonably small subset of the items were presented to any one subject. Participants who elected to respond to the creativity assessment were administered the complete creative achievement questionnaire.

Creativity. An expanded version of the Creative Achievement Questionnaire was used to assess creative achievements (see the Appendix). Participants completed this supplementary questionnaire after they had completed the main SAPA-Project personality assessment. The CAQ includes 10 domains, namely (1) inventions and innovations, (2) music, (3) theater/TV/film, (4) scientific discovery, (5) creative writing, (6) dance, (7) culinary arts, (8) visual art, (9) humor, and (10) architecture. The CAQ was expanded by adding response choices 
for frequency to those questions that require skill beyond the "training" questions of the CAQ. Within each domain, each item was weighted consistent with the published version of the CAQ, though participants were able to receive a much wider range of scores in our version given the additional information about the frequency of achievements. Scores for each domain were standardized and log-transformed in an effort to address variation in the range of possible scores across domains and the high positive skew of the raw scores.

Cognitive Ability. The International Cognitive Ability Resource, a public-domain measure of cognitive ability, includes 60 items of four item types: Matrix Reasoning (11 items), Verbal Reasoning (16 items), Letter-Number Series (9 items), and Three-Dimensional Rotation items (24 items) (Condon \& Revelle, 2014). Participants were administered random 16 item subsets of the measure ("ICAR60"). The ICAR measure is not intended as a substitute for an extended one-on-one assessment of cognitive abilities (e.g., the WAIS-IV; Hartman, 2009), but rather a validated brief measure for construct-level evaluations of cognitive ability outside of neuropsychological administration settings (Dworak et al., 2020; Revelle et al., 2020; Young et al., 2019).

Personality. The 100 items of the IPIP 100 Big Five Factor Markers ("IPIP100", Goldberg, 1999) were used to assess the Big Five personality traits. The IPIP100 includes 20 items each for the scales of Extraversion, Agreeableness, Conscientiousness, Emotional Stability, and Intellect.

Interests. The Oregon Vocational Interest Scales (ORVIS) are a public-domain selfreport measure of vocational interests (Pozzebon et al., 2010). The 92 items measure eight dimensions of vocational interests: Leadership, Organization, Altruism, Creativity, Analysis, Producing, Adventuring, and Erudition. 


\section{Analyses}

All analyses were conducted in R (R Development Core Team, 2019). For the personality, cognitive ability, and interest scales, item response theory-based scores were calculated for each respondent using the psych package (version 1.9.12.31, Revelle, 2019) in R. Evaluations of the psychometric properties of the scales included reporting on the internal consistencies (a) and general factor saturation (Whierarchical; Zinbarg et al., 2007; Zinbarg et al., 2006), also using the psych package (Revelle, 2019).

To evaluate the nature and extent of differences among respondents to the creative achievement questionnaire relative to the full sample, group means and standard deviations were compared for those who completed the questionnaire and those who did not. To evaluate the relationship between creative achievement and cognitive ability, we tested both linear and nonlinear Loess fits (Cleveland et al., 1992) for a model predicting CAQ Total Score from ICAR60 score. To evaluate the evidence for the threshold hypothesis, we aggregated the data and found the mean CAQ total score for each possible cognitive ability score using the 16-item ICAR60 measure.

To evaluate the relationship between creative achievement and age, we tested linear, nonlinear, and aggregated mean models for the CAQ total score predicted by age. It is important to note that the CAQ assigns an increasing number of points to creative achievements that are assumed to be more difficult based on level of recognition and the time presumably required in training or practice to achieve the accomplishment. Moreover, the CAQ multiplies this score by the number of times that the accomplishment has been achieved. It was the possibility of increasingly higher scores at higher levels of achievement that motivated considerations of nonlinear associations. 
The examination of how personality, vocational interests, and cognitive ability together account for variance in creative achievements was conducted through a series of linear regressions. First, each domain CAQ score and total CAQ score was predicted using each of the Big Five, cognitive ability (ICAR), and interest scales separately. Then, four multiple regression analyses were conducted to predict each domain score and total CAQ score by (i) Big Five traits (all five scales together); (ii) total ICAR score; (iii) ORVIS (all eight scales together); and (iv) Big Five, ICAR, and ORVIS items together. All of these controlled for age and gender. Lastly, participants with the top $25 \%$ scores in each domain were identified. The mean scores of these high achievers for the personality, cognitive ability, and vocational interest scales were identified, thereby creating a profile of the average high achiever in each domain.

The data are available in the public domain at [blinded] and the analytic code is provided as Supplementary Material.

\section{Results}

Internal consistencies for the personality, cognitive ability, and vocational interest scales are reported in Table 3 . All of the scales demonstrated high consistency among the items ( $\alpha=$ 0.76 - 0.94). The degree of general factor saturation (Whierarchical; Zinbarg et a., 2007; Zinbarg et al., 2006) varied considerably and was lower for vocational interests ( hierarchical $=0.55-0.72$ ) than either the Big Five $(\omega$ hierarchical $=0.61-0.80)$ or cognitive ability $(\omega$ hierarchical $=0.64-0.81)$.

\section{[INSERT TABLE 3]}

Evaluation of the nature and extent of differences among respondents to the creative achievement questionnaire relative to the full sample showed that the CAQ respondents differed from the baseline SAPA users on many dimensions (Figure 1). Compared to the baseline, CAQ 
respondents had lower scores for all Big Five traits except Intellect. They also scored more highly on the cognitive ability measure and more highly endorsed the vocational interest scales of Productive, Analytical, Erudition, and Artistic.

[INSERT FIGURE 1]

Among CAQ respondents, CAQ Total Scores demonstrated a small positive correlation with ICAR60 scores $(r=.12,95 \%$ CI $[0.10,0.16]$. Allowing for a nonlinear relationship by drawing a Loess regression line on the scatterplot did not indicate a leveling off after any ICAR60 score threshold (Figure 2). Instead, the relationship remained consistent through two standard deviations above the mean.

\section{[INSERT FIGURE 2]}

When evaluating the relationship between creative achievement and age, preliminary results indicated that participants in their twenties had higher total creative achievement scores than older participants. To evaluate the extent to which these results were driven by the most easily endorsed items in each domain, additional analyses were conducted where the easiest items were assigned a score of zero; this was done using the easiest 1, then 2, 3, and 4 items. As fewer items counted toward domain and total creativity scores, the mean scores decreased substantially. However, with each additional easily-endorsed item removed, the relationship between age and creative achievement score went from a negative relationship to slightly positive (Figures 3-4). Specifically, the line of best fit slope is $-.022\left(r=.07, R^{2}=.004\right)$ when 
including all items, but $.017\left(r=.07, R^{2}=.005 ; p<.001\right.$ for the difference in slopes $)$ when excluding the four most easily endorsed items from each domain.

\section{[INSERT FIGURE 3]}

\section{[INSERT FIGURE 4]}

Table 4 shows the standardized beta-coefficients and effect sizes of the Big Five, ICAR, and Vocational Interest traits separately and combined on Creative Achievement, all of which are controlled for age and gender. The amount of variance that can be accounted for with consideration to temperament, cognitive ability, and vocational interests, differs significantly between creativity domains. The domains with the highest variances accounted for by the traits were Inventions and Innovations $\left(R^{2}=.23\right)$, Scientific Discovery $\left(R^{2}=.19\right)$, Creative Writing $\left(R^{2}\right.$ $=.18)$, and Visual Arts $\left(R^{2}=.16\right)$. Dance $\left(R^{2}=.06\right)$ and Architecture $\left(R^{2}=.04\right)$ are the domains with the lowest variance accounted for by temperament, cognitive ability, and vocational interests. Among the aspects of individual differences, vocational interests are the strongest predictors of creative achievement across all domains except Humor. Achievements in some creativity domains were much better predicted using all three individual differences domains.

\section{[INSERT TABLE 4]}

The zero-order correlation matrix (Figure 5) indicates that of the creative domains, Science and Inventions are most related to cognitive ability. Intellect is also highly correlated 
with creative achievement across domains. Another notable correlation is Extraversion with Humor and Theater/TV/Film.

\section{[INSERT FIGURE 5]}

Since the regression analyses indicated that vocational interests are the greatest predictors of achievement across creativity domains, plotting the mean scores of the top $25 \%$ achievers in each domain provided a good visualization of whether interests differ across domains. Figure 6 demonstrates variance in ORVIS scale scores by domain. There is less spread in mean scores on some vocational interest scales (e.g., Altruistic and Leadership) than others (e.g., Analytical, Erudition, and Artistic). For example, high achievers in the Science and Invention domains endorse the Analytical scale more and the Artistic scale less than high achievers in the other domains. High achievers in Art endorse the Organizational and Leadership scales less than other high creative achievers, but have the highest mean score on the Artistic scale, along with the Music, Theater/TV/Film, and Humor domains.

[INSERT FIGURE 6]

\section{Discussion}

Analyses of this large-scale data collection on creative achievement yielded several interesting findings. First, meaningful differences were found between individuals who only responded to the general SAPA-Project personality inventory and those who also went on to take 
the optional Creative Achievement Questionnaire. As expected, a self-selection bias was evident among CAQ responders in that their self-reports indicated higher levels of education and cognitive ability, higher levels of interest in ideas, and higher average endorsement levels for personality content commonly associated with creativity (i.e., "Spend time reflecting on things," "Have a vivid imagination"). These differences are important because, while the remaining analyses made use of an adequately large and diverse sample, the generalizability of the observed effects is unclear. This is a limitation of the subsequent results, but it also serves to inform findings related to creative achievement beyond the current study. Creativity research involving high-achievers - a low-base rate group in the general population, by definition - will often naturally invoke similar selection effects unless random sampling procedures are carefully implemented.

Among people who responded to the CAQ, the relationship between cognitive ability and creative achievement was clear. Individuals with higher ICAR60 scores also had, on average, higher total creative achievement scores. There was no evidence for non-linearity in the regression and thus no support for the threshold hypothesis; creative achievement did not plateau at any level of ICAR60 scores. Rather, higher cognitive ability scores continue to correlate at a consistent level with higher creative achievement scores.

With respect to age, there was initially no evidence of a meaningful relationship to creative achievement using the CAQ. After recognizing that the association may depend on the difficulty (i.e., the magnitude) of the achievements, we repeated our analyses iteratively after removing the most easily endorsed items from each domain. At each step, the results became increasingly more positive; a small but statistically significant effect was observed when removing the 4 most easily endorsed items. These results indicate that the nature of high scores 
on the CAQ is quite different across ages. Younger participants with high scores tended to have relatively low scores in many domains while older participants with high scores were more likely to report relatively higher scores in one or a few domains. It is also notable that relatively few young participants had multiple highly regarded creative accomplishments (i.e., the most difficult items to endorse in each domain), suggesting that the opportunity to accumulate high achievements is itself a function of time and experience.

Beyond these general relationships between overall creative achievement, cognitive ability, and age, the data showed marked variability across the psychological individual differences domains in terms of predictive strength for creative achievement by domain. In every domain, vocational interests were more predictive of creative achievement than the Big Five traits and cognitive ability, though the relative strength of interests ranged from explaining about the same variance as the Big Five and cognitive ability (e.g., Architecture \& Design) to explaining nearly all of the variance accounted for by these three broad domains together (e.g., Visual Arts). Substantial variation within the individual differences domains was also evident across the different achievement types. For example, high interest in Analytical vocations predicts high achievement in Science and Innovation. Artistic and Leadership interests, on the other hand, are the top predictors for achievement in Theater/TV/Film.

These findings collectively support our hypothesis that creativity is domain-specific, though some traits were relatively predictive of creative achievement regardless of domain. Consistent with previous studies (McCrae, 1987; King et al., 1996), Intellect has a strong positive relationship with creativity, and this holds true across domains in our study. Like other studies (Silvia et al., 2011), we also found a positive relationship between Extraversion and creative achievement. 


\section{Conclusion}

Using the large sample of SAPA-Project participants who completed the additional Creative Achievement Questionnaire, we were able to link creative achievement with individual differences in Big Five traits, cognitive ability, and vocational interests. Some factors, such as intellect, extraversion, and cognitive ability are consistently associated with creative achievement. Even with this general positive association, the relative importance of a given trait differs for the domains we investigated in this study. In other words, the prediction of creative achievement based on self-reported individual differences depends on both general traits (intellect and high cognitive ability) as well as those which are specific to each achievement domain (i.e., interests).

We encountered several limitations in this study, mainly related to sampling constraints that impaired the generalizability of the results. First, there was a selection effect caused by the voluntary nature of responding to the CAQ items. This introduced the sampling bias that was evaluated in Study 1. Second, there was a more subtle bias indicated by variable endorsement rates across the creativity domains. For example, many more participants had at least one accomplishment in Culinary Arts than in Architecture (2,220 vs 484). This suggests that creative achievements are not equivalently likely to be attained across domains (at least in this sample of respondents). Many factors may contribute to this circumstance, ranging from limitations of the CAQ measure to much broader societal factors. Finally, because answers were self-reported, it is impossible to evaluate the validity of the responses. While social desirability was unlikely to have a strong influence on the reporting of achievements (all reports were anonymous and confidential), there are several other possible sources of self-report bias (inaccurate recall, differences in interpretation, factors affecting self-evaluation, etc.). 
Future directions should continue to improve upon the methods used to evaluate creative achievement. We believe the scoring of the CAQ suggested here is an improvement over the original scoring because it more thoroughly accounts for the number of times a given achievement is accomplished. However, the results from the age study suggest that the proposed scoring may favor participants that have shallow interests in several domains of creativity over those who have more significant achievements in one (or more) domain. Future studies should investigate this further and aim to eliminate this conflation of scores. Possible solutions for this challenge might include further revision of the questionnaire, the introduction of new scoring methods based on item response theory, or the use of more recently developed creative achievement inventories, such as the Inventory of Creative Activities and Achievements (ICAA; Diedrich, Jauk, Silvia, Gredlein, Neubauer, \& Benedek, 2017).

Future research should also give greater consideration to the ways that individual differences domains may overlap or interact across the lifespan. This work should include both measurement initiatives focused on more holistic approaches to individual differences assessment (Condon, 2014; Condon, 2018; Condon et al., 2020) as well as studies of the extent to which integrated profiles of psychological individual differences can predict important life outcomes (Cronin et al., 2019). By focusing on more than a single domain of individual differences (be it the Big Five, cognitive ability, interests, or other topics), psychologists will form a more nuanced understanding of whole persons and the outcomes they experience. If the aim is to increase creative achievement across society at large, we hope that research in this area will be advanced by the findings described herein and our recommendations for subsequent improvements in measurement. 


\section{References}

Ackerman, P. L., \& Kanfer, R. (2004). Cognitive, affective, and conative aspects of adult intellect within a typical and maximal performance framework. In D. Y. Dai \& R. J. Sternberg (pp. 119-141), Motivation, emotion, and cognition: Integrative perspectives on intellectual functioning and development. Routledge: England, UK.

Alpaugh, P., \& Birren, J. (1977). Variables affecting creative contributions across the adult life span. Human Development, 20, 240-248. doi: 10.1159/000271559

Armstrong, P. I., Day, S. X., McVay, J. P., \& Rounds, J. (2008). Holland's RIASEC model as an integrative framework for individual differences. Journal of Counseling Psychology, 55(1), 1-18. DOI: $10.1037 / 0022-0167.55 .1 .1$

Ashton, M. C., Lee, K., \& Goldberg, L. R. (2007). The IPIP-HEXACO scales: An alternative, public-domain measure of the personality constructs in the HEXACO model. Personality and Individual Differences, 42(8), 1515-1526. doi:10.1016/j.paid.2006.10.027

Baer, J., \& Kaufman, J. C., (2005). Bridging generality and specificity: The amusement park theoretical (APT) model of creativity, Roeper Review, 27(3), 158-163. doi: $10.1080 / 02783190509554310$

Batey, M., \& Furnham, A. (2006). Creativity, intelligence, and personality: a critical review of the scattered literature. Genetic, Social, and General Psychology Monographs, 132(4), 355429. doi: 10.3200/MONO.132.4.355-430

Beaty, R. E., Kaufman, S. B., Benedek, M., Jung, R. E., Kenett, Y. N., Jauk, E., .. \& Silvia, P. J. (2016). Personality and complex brain networks: The role of openness to experience in default network efficiency. Human Brain Mapping, 37(2), 773-779.

https://doi.org/10.1002/hbm.23065 
Burch, G. S. J., Pavelis, C., Hemsley, D. R., \& Corr, P. J. (2006). Schizotypy and creativity in visual artists. British Journal of Psychology, 97(2), 177-190. doi: $10.1348 / 000712605 \times 60030$

Carson, S., Peterson, J. B., \& Higgins, D. M. (2005). Reliability, validity , and factor structure of the Creative Achievement Questionnaire, Creativity Research Journal, 17(1), 37-50. doi: 10.1207/s15326934crj1701_4

Cleveland, W. S., Grosse, E., \& Shyu, W. M. (1992). Local regression models. In: Chambers, J. M. \& Hastie, T. J. Statistical Models in S. CRC Press, Inc. Boca Raton, FL.

Colangelo, N., Kerr, B., Hallowell, K., Huesman, R., \& Gaeth, J. (1992). The Iowa Inventiveness Inventory: Toward a measure of mechanical inventiveness. Creativity Research Journal, 5(2), 157-163. doi: 10.1080/10400419209534429

Condon, D. M. (2014). An organizational framework for the psychological individual differences: integrating the affective, cognitive, and conative domains. (Doctoral dissertation, Northwestern University).

Condon, D. M. (2018). The SAPA Personality Inventory: An empirically-derived, hierarchicallyorganized self-report personality assessment model. PsyArXiv, 1-444.

Cronin, R. M., Jerome, R. N. Mapes, B., Andrade, R., Johnston, R., Ayala, J., Schlundt, D., Bonnet, K., Kri- palani, S., Goggins, K., Wallston, K. A., Couper, M. P., Elliott, M. R., Harris, P., Begale, M., Munoz, F., Lopez-Class, M., Cella, D., Condon, D. M., Alonso, A., AuYoung, M., Mazor, K., Mikita, S., Manganiello, M., Borselli, N., Fowler, S., McClain, J., Rutter, J. L., Dishman, E., Denny, J. C., Karlson, E., Ahmedani, B. K., O’Donnell, C., the Vanderbilt University Medical Center Pilot Team, and the Participant Provided Information 
Committee. (2019). Development of the Initial Surveys for the All of Us Research Program. Epidemiology. https://doi.org/10.1097/EDE.0000000000001028

Condon, D., \& Revelle, W. (2014). The International Cognitive Ability Resource: Development and initial validation of a public-domain measure. Intelligence, 43, 52-64. doi: 10.1016/j.intell.2014.01.004.

Condon, D. M., Wood, D., Mõttus, R., Booth, T., Costantini, G., Greiff, S., ... \& Zimmermann, J. (in press). Bottom up construction of a personality taxonomy. European Journal of Psychological Assessment.

DeYoung, C. G., Peterson, J. B., \& Higgins, D. M. (2005). Sources of openness/intellect: cognitive and neuropsychological correlates of the fifth factor of personality. Journal of Personality, 73(4), 825-858. doi:10.1111/j.1467-6494.2005.00330.x

DeYoung, C. G., Quilty, L. C., Peterson, J. B., \& Gray, J. R. (2014). Openness to experience, intellect, and cognitive ability. Journal of Personality Assessment, 96(1), 46-52. doi: $10.1080 / 00223891.2013 .806327$

Diedrich, J., Jauk, E., Silvia, P. J., Gredlein, J. M., Neubauer, A. C., \& Benedek, M. (2018). Assessment of real-life creativity: The Inventory of Creative Activities and Achievements (ICAA). Psychology of Aesthetics, Creativity, and the Arts, 12(3), 304-316. https://doi.org/10.1037/aca0000137

Dworak, E. M., Revelle, W., Doebler, P., \& Condon, D. M. (2021). Using the international cognitive ability resource as an open source tool to explore individual differences in cognitive ability. Personality and Individual Differences, 169, 109906. https://doi.org/10.1016/j.paid.2020.109906 
Eynsenck, H. J. (1995). Genius: the natural history of creativity. Cambridge, UK: Cambridge University Press.

Feist, G. J., (1993). A structural model of scientific eminence. Psychological Science, 4(6), 366371. doi: 10.1111/j.1467-9280.1993.tb00583.x

Feist, G. (1998). A meta-analysis of personality in scientific and artistic creativity. Personality and Social Psychology Review, 2(4), 290-309. doi:10.1207/s15327957pspr0204

Feist, G. J. (2006). How development and personality influence scientific thought, interest, and achievement. Review of General Psychology, 10(2), 163-182. doi:10.1037/10892680.10.2.163

Furnham, A., \& Bachtiar, V. (2008). Personality and intelligence as predictors of creativity. Personality and Individual Differences, 45(7), 613-617. doi:10.1016/j.paid.2008.06.023

Goldberg, L. R. (1993). The structure of phenotypic personality traits. American Psychologist, 48(1), 26-34. https://doi.org/10.1037/0003-066X.48.1.26

Goldberg, L. (1999). A broad-bandwidth, public domain, personality inventory measuring the lower-level facets of several five-factor models. In I. Mervielde, I.J. Deary, F. De Fruyt, \& F. Ostendorf, Personality Psychology in Europe. (pp. 7-28). Tilburg University Press.

Guilford, J. P. (1959). Personality. New York: McGraw-Hill.

Guilford, J. P., (2011). Creativity: yesterday, today and tomorrow. The Journal of Creative Behavior, 1(1), 3-14. doi: 10.1002/j.2162-6057.1967.tb00002.x

Hartman, D. E. (2009). Wechsler Adult Intelligence Scale IV (WAIS IV): return of the gold standard. Applied Neuropsychology, 16(1), 85-87. https://doi.org/10.1080/09084280802644466 
Hocevar, D. (1979). The development of the Creative Behavior Inventory (CBI). Paper presented at the 1979 conference of the Rocky Mountain Psychological Association, Las Vegas, Nevada. Retrieved from http://eric.ed.gov/?id=ED170350

Hocevar, D. (1980). Intelligence, divergent thinking, and creativity. Intelligence, 4(1), 25-40. doi:10.1016/0160-2896(80)90004-5

Jauk, E., Benedek, M., Dunst, B., \& Neubauer, A. C. (2013). The relationship between intelligence and creativity: New support for the threshold hypothesis by means of empirical breakpoint detection. Intelligence, 41(4), 212-221. doi:10.1016/j.intell.2013.03.003

Kaufman, J. C., Cole, J. C., \& Baer, J. (2009). The construct of creativity: structural model for self-reported creativity ratings. The Journal of Creative Behavior, 43(2), 119-134. doi:10.1002/j.2162-6057.2009.tb01310.x

Kaufman, S. B., Quilty, L.C., Grazioplene, R.G., Hirsh, J.B., Gray, J.R., Peterson, J.B., \& DeYoung, C.G. (2016). Openness to experience and intellect differentially predict creative achievement in the arts and sciences: openness, intellect, and creativity. Journal of Personality, 84, 248-258. doi: 10.1111/jopy.12156

King, L. A., Walker, L. M., Broyles, S. J. (1996). Creativity and the Five-Factor Model. Journal of Research in Personality, 30(2), 189-203. doi:10.1006/jrpe.1996.0013

Lehman, H. (1953). Age and achievement. In H. R. Moody, Aging: Concepts and Controversies (pp. 85-91). London: Pine Forge Press.

Li, W., Li, X., Huang, L., Kong, X., Yang, W., Wei, D., ... \& Liu, J. (2014). Brain structure links trait creativity to openness to experience. Social Cognitive and Affective Neuroscience, 10(2), 191-198. https://doi.org/10.1093/scan/nsu041 
Lord, F. M. (1955). Estimating test reliability. ETS Research Bulletin Series, 15(1), 1-17. doi: 10.1002/j.2333-8504.1955.tb00054.x

MacKinnon, D. W. (1962). The nature and nurture of creative talent. American Psychologist, 17, 484-495. doi: 10.1037/h0046541

McCrae, R. R. (1987). Creativity, divergent thinking, and openness to experience. Journal of Personality and Social Psychology, 52(6), 1258-1265. doi:10.1037/0022-3514.52.6.1258

McGrew, K. S. (2009). CHC theory and the human cognitive abilities project: Standing on the shoulders of the giants of psychometric intelligence research. Intelligence, 37, 1-10. https://doi.org/10.1016/j.intell.2008.08.004

Nusbaum, B. E. C., \& Silvia, P. J. (2011). Are intelligence and creativity really so different? Fluid intelligence, executive processes, and strategy use in divergent thinking. Intelligence, 39, 36-45. doi: 10.1016/j.intell.2010.11.002

Panksepp, J. (1998). Affective neuroscience: The foundations of human and animal emotions. New York: Oxford University Press.

Peterson, J. B., \& Carson, S. (2000). Latent inhibition and openness to experience in a highachieving student population. Personality and Individual Differences, 28, 323-332. doi: $10.1016 / \mathrm{S} 0191-8869(99) 00101-4$

Peterson, J. B., Smith, K. W., \& Carson, S. (2002). Openness and Extraversion are associated with reduced latent inhibition: Replication and commentary. Personality and Individual Differences, 33, 1137-1147. doi:10.1016/S0191-8869(02)00004-1

Pozzebon, J. A., Visser, B. A., Ashton, M. C., Lee, K., \& Goldberg, L. R. (2010). Psychometric characteristics of a public-domain self-report measure of vocational interests: the Oregon 
Vocational Interest Scales. Journal of Personality Assessment, 92(2), 168-174. doi:10.1080/00223890903510431

Plucker, J. A. (2004). Generalization of creativity across domains: Examination of the method effect hypothesis. Journal of Creative Behavior, 38, 1-12. doi: 10.1002/j.21626057.2004.tb01228.x

Plucker, J. A., (2005). The (relatively) generalist view of creativity. In J. C. Kaufman, \& J. Baer (Eds.), Creativity across domains: Faces of the muse (pp. 307-312). London: Lawrence Erlbaum Associates.

Pozzebon, J. A., Visser, B. A., Ashton, M. C., Lee, K., \& Goldberg, L. R. (2010). Psychometric characteristics of a public-domain self-report measure of vocational interests: The oregon vocational interest scales. Journal of Personality Assessment, 92(2), 168-174. https://doi.org/10.1080/00223890903510431

R Development Core Team (2019). R: A language and environment for statistical computing. R Foundation for Statistical Computing, Vienna, Austria. URL http://www.R-project.org/

Rad, M. S., Martingano, A. J., \& Ginges, J. (2018). Toward a psychology of Homo sapiens: Making psychological science more representative of the human population. Proceedings of the National Academy of Sciences, 115(45), 11401-11405. https://doi.org/10.1073/pnas.1721165115

Revelle, W. (2019). psych: Procedures for Personality and Psychological Research, Northwestern University: Evanston, Illinois, USA, https://cran.rproject.org/web/packages/psych/index.html Version $=1.9 .12$.

Revelle, W., Condon, D. M., Wilt, J., French, J. A., Brown, A., \& Elleman, L. G. (2017). Weband phone-based data collection using planned missing designs. In N. G. Fielding, R. M. 
Lee, \& G. Blank (Eds.), The SAGE Handbook of Online Research Methods (pp. 578-594). https://doi.org/10.4135/9781473957992.n33

Revelle, W., Dworak, E. M., \& Condon, D. (2020). Cognitive ability in everyday life: The utility of open-source measures. Current Directions in Psychological Science, 29(4), 358-363. https://doi.org/10.1177/0963721420922178

Robertson, K. F., Smeets, S., Lubinski, D., \& Benbow, C. P. (2010). Beyond the Threshold Hypothesis: Even among the gifted and top math/science graduate students, cognitive abilities, vocational interests, and lifestyle preferences matter for career choice, performance, and persistence. Current Directions in Psychological Science, 19(6), 346-351. doi:10.1177/0963721410391442

Savi, A. O., Marsman, M., van der Maas, H. L., \& Maris, G. K. (2019). The wiring of intelligence. Perspectives on Psychological Science, 14(6), 1034-1061. https://doi.org/10.1177/1745691619866447

Silvia, P. J., Kaufman, J. C., \& Pretz, J. E. (2009). Is creativity domain-specific? Latent class models of creative accomplishments and creative self-descriptions. Psychology of Aesthetics, Creativity, and the Arts, 3(3), 139 -148. doi: 10.1037/a0014940

Silvia, P. J., Kaufman, J. C., \& Wigert, B. (2011). Cantankerous creativity: Honesty-Humility, Agreeableness, and the HEXACO structure of creative achievement. Personality and Individual Differences, 51, 687-689. doi: 10.1016/j.paid.2011.06.011

Silvia, P. J., Nusbaum, E. C., Berg, C., Martin, C., \& O'Conner, A. (2009). Openness to experience, plasticity, and creativity: Exploring lower-order, higher-order, and interactive effects. Journal of Research in Personality, 43(6), 1087-1090. doi:10.1016/j.jrp.2009.04.015 
Silvia, P. J., Wigert, B., Reiter-Palmon, R., Kaufman, J. C. (2012). Assessing creativity with selfreport scales: A review and empirical evaluation. Psychology of Aesthetics, Creativity, and the Arts, 6(1), 19-34. doi: 10.1037/a0024071

Silvia, P. J., Winterstein, B. P., Willse, J. T., Barona, C. M., Cram, J. T., Hess, K. I., ... Richard, C. A. (2008). Assessing creativity with divergent thinking tasks: Exploring the reliability and validity of new subjective scoring methods. Psychology of Aesthetics, Creativity, and the Arts, 2(2), 68-85. doi:10.1037/1931-3896.2.2.68

Simonton, D. K. (1988). Age and outstanding achievement: What do we know after a century of research? Psychological Bulletin, 104(2), 251-67. doi: 10.1037/0033-2909.104.2.251

Sternberg, R. J., \& Lubart, T. I. (1999). The concept of creativity: Prospects and paradigms. In R. J. Sternberg (Ed.), Handbook of creativity (pp. 2-15). NY: Cambridge University Press.

Taylor, C. W., \& Ellison, R. L. (1967). Biographical predictors of scientific performance. Science, 155, 1075-1079. doi: 10.1126/science.155.3766.1075

Torrance, E. P. (1972). Career patterns and peak creative achievements of creative high school students twelve years later. Gifted Child Quarterly, 16, 75-88. https://doi.org/10.1177/001698627201600201

Torrance, E. P. (1974). The Torrance Tests of Creative Thinking - norms- technical manual research edition - verbal tests, forms $A$ and $B$ - figural tests, forms $A$ and $B$. Princeton, NJ: Personnel Press.

Torrance, E. P. (1987). Future career image as a predictor of creative achievement in a 22-year longitudinal study. Psychological Reports, 60, 574. doi: 10.2466/pr0.1987.60.2.574

Trapnell, P. D. (1994). Openness versus intellect: a lexical left turn. European Journal of Personality, 8(4), 273-290. doi: 10.1002/per.2410080405 
Wilt, J., Condon, D. M., \& Revelle, W. (2012). Telemetrics and online data collection: Collecting data at a distance. In B. Laursen, T. D. Little, \& N. A. Card (Eds.), Handbook of developmental research methods (pp. 163-180). New York: Guilford Press.

Young, S. R., Keith, T. Z., \& Bond, M. A. (2019). Age and sex invariance of the International Cognitive Ability Resource (ICAR). Intelligence, 77, 101399. https://doi.org/10.1016/j.intell.2019.101399

Zinbarg, R., Yovel, I. \& Revelle, W. (2007). Estimating omega for structures containing two group factors: Perils and prospects. Applied Psychological Measurement. 31(2), 135-157. doi: $10.1177 / 0146621606291558$

Zinbarg, R., Yovel, I., Revelle, W. \& McDonald, R. (2006). Estimating generalizability to a universe of indicators that all have one attribute in common: A comparison of estimators for omega. Applied Psychological Measurement, 30, 121-144. doi:10.1177/0146621605278814

Zuckerman, H. (1996). Scientific Elite: Nobel Laureates in the United States. New Brunswick, NJ: Transaction Publishers. 
Table 1. Participants by Educational Attainment Level.

\begin{tabular}{|c|c|c|c|c|c|c|c|c|}
\hline & \multicolumn{4}{|c|}{ CAQ Respondents ${ }^{1}$} & \multicolumn{4}{|c|}{ Non-Responders $^{2}$} \\
\hline & $\begin{array}{l}\% \text { of } \\
\text { total }\end{array}$ & $\begin{array}{c}\text { Mean } \\
\text { age }\end{array}$ & $\begin{array}{l}\text { Median } \\
\text { age }\end{array}$ & $\begin{array}{c}\% \\
\text { Female }\end{array}$ & $\begin{array}{l}\% \text { of } \\
\text { total }\end{array}$ & $\begin{array}{c}\text { Mean } \\
\text { age }\end{array}$ & $\begin{array}{l}\text { Median } \\
\text { age }\end{array}$ & $\begin{array}{c}\% \\
\text { Female }\end{array}$ \\
\hline Less than $12 \mathrm{yrs}$ & 9.2 & 17.1 & 16.0 & 63.7 & 12.2 & 17.1 & 17.0 & 60.2 \\
\hline High school graduate & 7.4 & 23.9 & 19.0 & 55.8 & 7.5 & 22.4 & 18.0 & 50.6 \\
\hline $\begin{array}{l}\text { Currently in } \\
\text { college/university }\end{array}$ & 32.3 & 24.0 & 21.0 & 64.6 & 37.5 & 23.8 & 21.0 & 64.6 \\
\hline $\begin{array}{l}\text { Some college/university, but } \\
\text { did not graduate }\end{array}$ & 8.7 & 32.5 & 30.0 & 54.0 & 5.8 & 31.6 & 28.0 & 50.5 \\
\hline College/university degree & 18.8 & 33.0 & 29.0 & 55.2 & 12.9 & 32.0 & 28.0 & 55.9 \\
\hline $\begin{array}{l}\text { Currently in graduate or } \\
\text { professional school }\end{array}$ & 6.8 & 29.7 & 27.0 & 67.7 & 4.7 & 28.8 & 26.0 & 57.9 \\
\hline $\begin{array}{l}\text { Graduate or professional } \\
\text { degree }\end{array}$ & 12.4 & 40.4 & 37.0 & 65.3 & 7.2 & 38.2 & 35.0 & 57.0 \\
\hline Not specified & 4.4 & & & & 9.8 & & & \\
\hline
\end{tabular}

\footnotetext{
${ }^{1}$ 3,841 SAPA participants who also completed the Creative Achievement Questionnaire (CAQ).

${ }^{2} 63,486$ SAPA participants who elected not to complete the CAQ.
} 
Table 2. Participants by Race/Ethnicity.

\begin{tabular}{|c|c|c|c|c|c|}
\hline & \multicolumn{2}{|c|}{ CAQ Respondents ${ }^{1}$} & \multicolumn{2}{|c|}{ Non-Responders ${ }^{2}$} & \multirow[b]{2}{*}{$\%$ of U.S. ${ }^{3}$} \\
\hline & Count & $\%$ & Count & $\%$ & \\
\hline African-American & 82 & 2.1 & 3,363 & 5.3 & 12.2 \\
\hline Asian-American & 108 & 2.8 & 2,023 & 3.2 & 4.4 \\
\hline Hispanic-American & 126 & 3.3 & 3,472 & 5.5 & 15.7 \\
\hline Native-American & 15 & 0.4 & 259 & 0.4 & .90 \\
\hline White/Caucasian & 1,735 & 45.2 & 25,938 & 40.9 & 64.9 \\
\hline Multi-ethnic & 151 & 3.9 & 2,402 & 3.8 & 1.7 \\
\hline Other & 28 & 0.7 & 705 & 1.1 & \\
\hline Not specified & 1,596 & 41.6 & 25,324 & 39.9 & \\
\hline
\end{tabular}

${ }_{1}^{1}$ 3,841 SAPA participants who also completed the CAQ.

${ }^{2}$ 63,486 SAPA participants who elected not to complete the CAQ.

${ }^{3} 2009$ U.S. data from the U.S. Census Bureau 
Table 3. Internal consistencies for the temperament, cognitive ability and vocational interest scales.

\begin{tabular}{lcccc}
\hline & $\alpha$ & $\omega \mathrm{h}$ & $\omega \mathrm{t}$ & items \\
\hline Personality scales & & & & \\
Agreeableness & 0.92 & 0.78 & 0.93 & 20 \\
Conscientiousness & 0.91 & 0.66 & 0.93 & 20 \\
Extraversion & 0.94 & 0.80 & 0.95 & 20 \\
Emotional Stability & 0.93 & 0.76 & 0.94 & 20 \\
Intellect & 0.89 & 0.61 & 0.91 & 20 \\
& & & & \\
Cognitive ability scales & & & & \\
ICAR Combined & 0.94 & 0.69 & 0.95 & 60 \\
Letter-Number Series & 0.79 & 0.71 & 0.81 & 9 \\
Matrix Reasoning & 0.77 & 0.69 & 0.79 & 11 \\
3D Rotation & 0.94 & 0.81 & 0.95 & 24 \\
Verbal Reasoning & 0.77 & 0.64 & 0.79 & 16 \\
& & & & \\
Vocational interest scales & & & & \\
Productive & 0.82 & 0.68 & 0.87 & 10 \\
Adventurous & 0.79 & 0.57 & 0.84 & 10 \\
Analytical & 0.88 & 0.72 & 0.90 & 10 \\
Organizational & 0.85 & 0.63 & 0.88 & 13 \\
Leadership & 0.86 & 0.65 & 0.90 & 12 \\
Altruistic & 0.83 & 0.61 & 0.86 & 13 \\
Erudition & 0.76 & 0.58 & 0.80 & 10 \\
Artistic & 0.84 & 0.55 & 0.88 & 14 \\
\hline Note: a Cronbach's alpha, & & & & \\
\end{tabular}

Note: $\alpha=$ Cronbach's alpha, $\omega_{\mathrm{h}}=$ omega hierarchical, $\omega_{\mathrm{t}}=$ omega total 
Table 4. Regression Analyses of Individual Differences on CAQ Domain and Total Scores.

\begin{tabular}{|c|c|c|c|c|c|c|c|c|c|}
\hline & \multicolumn{3}{|c|}{$\frac{\text { CAQ Total }}{\frac{\text { Number of Regression Models }^{l}}{}}$} & \multicolumn{3}{|c|}{$\frac{\text { Inventions \& Innovations }}{\text { Number of Regression Models }{ }^{1}}$} & \multicolumn{3}{|c|}{$\frac{\text { Architecture, Design }}{\text { Number of Regression Models }}$} \\
\hline & 17 & 3 & 1 & 17 & 3 & 1 & 17 & 3 & 1 \\
\hline Intellect & $.34^{* * *}$ & $.31^{* * *}$ & $.19^{* * *}$ & $.22^{* * * *}$ & $.22^{* * *}$ & $.15^{* * *}$ & $.08^{* * *}$ & $.09^{* * *}$ & $.07^{* * *}$ \\
\hline Extraversion & $.20^{* * *}$ & $.12^{* * *}$ & $.12^{* * *}$ & $.06^{* * *}$ & .02 & .03 & .02 & .00 & -.01 \\
\hline Conscientiousness & -.01 & $-.04^{*}$ & .01 & .00 & .00 & -.01 & .01 & .01 & -.02 \\
\hline Emotional Stability & $.06^{* * *}$ & .00 & .01 & $.06^{* * *}$ & $.04^{*}$ & .01 & $.04^{*}$ & .03 & $.04^{*}$ \\
\hline Agreeableness & $.11^{* * *}$ & $.03^{*}$ & .04 & -.01 & $-.05^{* *}$ & .02 & -.01 & -.02 & .01 \\
\hline Big 5 Combined $R^{2}$ & & .14 & & & .15 & & & .02 & \\
\hline Letter-Number Series & $.08^{* * *}$ & .03 & .01 & $.09^{* * *}$ & .03 & -.01 & .00 & -.01 & -.04 \\
\hline Matrix Reasoning & $.07^{* * *}$ & .02 & -.01 & $.10^{* * * *}$ & $.03^{*}$ & .02 & .00 & -.01 & -.02 \\
\hline 3D Rotation & $.09^{* * *}$ & $.04^{*}$ & $.04^{*}$ & $.14^{* * *}$ & $.11^{* * *}$ & $.08^{* * *}$ & .02 & .02 & .01 \\
\hline Verbal Reasoning & $.10^{* * *}$ & $.07^{* * *}$ & $.04^{*}$ & $.09^{* * *}$ & $.03^{*}$ & .00 & $.03^{*}$ & .03 & .02 \\
\hline ICAR Combined $R^{2}$ & & .02 & & & .13 & & & .01 & \\
\hline Productive & $.20^{* * *}$ & $.08^{* * *}$ & $.09^{* * *}$ & $.19^{* * *}$ & $.14^{* * *}$ & $.13^{* * * *}$ & $.13^{* * *}$ & $.11^{* * *}$ & $.11^{* * *}$ \\
\hline Adventurous & $.12^{* * * *}$ & -.01 & -.02 & $.08^{* * * *}$ & -.02 & -.01 & $.05^{* *}$ & -.01 & -.01 \\
\hline Analytical & $.19^{* * * *}$ & $.12^{* * *}$ & $.08^{* * * *}$ & $.27^{* * *}$ & $.24^{* * *}$ & $.19^{* * *}$ & $.07^{* * *}$ & .03 & .02 \\
\hline Organizational & .02 & $-.07^{* * *}$ & $-.05^{* *}$ & $.07^{* * *}$ & -.02 & .00 & $.07^{* * *}$ & $.05^{*}$ & $.07^{* *}$ \\
\hline Leadership & $.23^{* * *}$ & $.16^{* * *}$ & $.07^{* * *}$ & $.13^{* * *}$ & $.10^{* * *}$ & $.05^{*}$ & $.06^{* * *}$ & .03 & .01 \\
\hline Altruistic & $.10^{*}$ & -.02 & $-.05^{* *}$ & -.03 & $-.10^{* * *}$ & $-.11^{* * *}$ & .00 & $-.04^{*}$ & $-.06^{* *}$ \\
\hline Erudition & $.22^{* * *}$ & $.04^{*}$ & $.05^{*}$ & $.04^{* *}$ & $-.05^{* *}$ & $-.05^{* *}$ & .03 & -.04 & -.03 \\
\hline Artistic & $.42^{* * *}$ & $.35^{* * *}$ & $.30^{* * *}$ & $.08^{* * *}$ & $.05^{* *}$ & .02 & $.11^{* * *}$ & $.10^{* * *}$ & $.08^{* * *}$ \\
\hline ORVIS Combined $R^{2}$ & & .23 & & & .20 & & & .03 & \\
\hline Big 5, ICAR, ORVIS Combined R ${ }^{2}$ & & & .28 & & & .23 & & & .04 \\
\hline
\end{tabular}

${ }^{1}$ Note: The values in the first creative domain column are the standardized regression coefficients from 17 separate regression analyses of the domain score predicted by each variable (e.g., Intellect), controlling for age and gender. The values in the second column are standardized regression coefficients and $R^{2}$ from 3 separate regressions analyses of the domain score predicted by each of the individual differences domains (Big Five, ICAR, ORVIS), controlling for age and gender. The values in the third creative domain column are the standardized regression coefficients and $R^{2}$ from a single regression analysis of the domain score predicted by age, gender, and all 17 of the factors combined.

${ }^{* * *} p<.001,{ }^{* *} p<.01,{ }^{*} p<.05$ 
Table 4 (continued). Regression Analyses of Individual Differences on CAQ Domain and Total Scores.

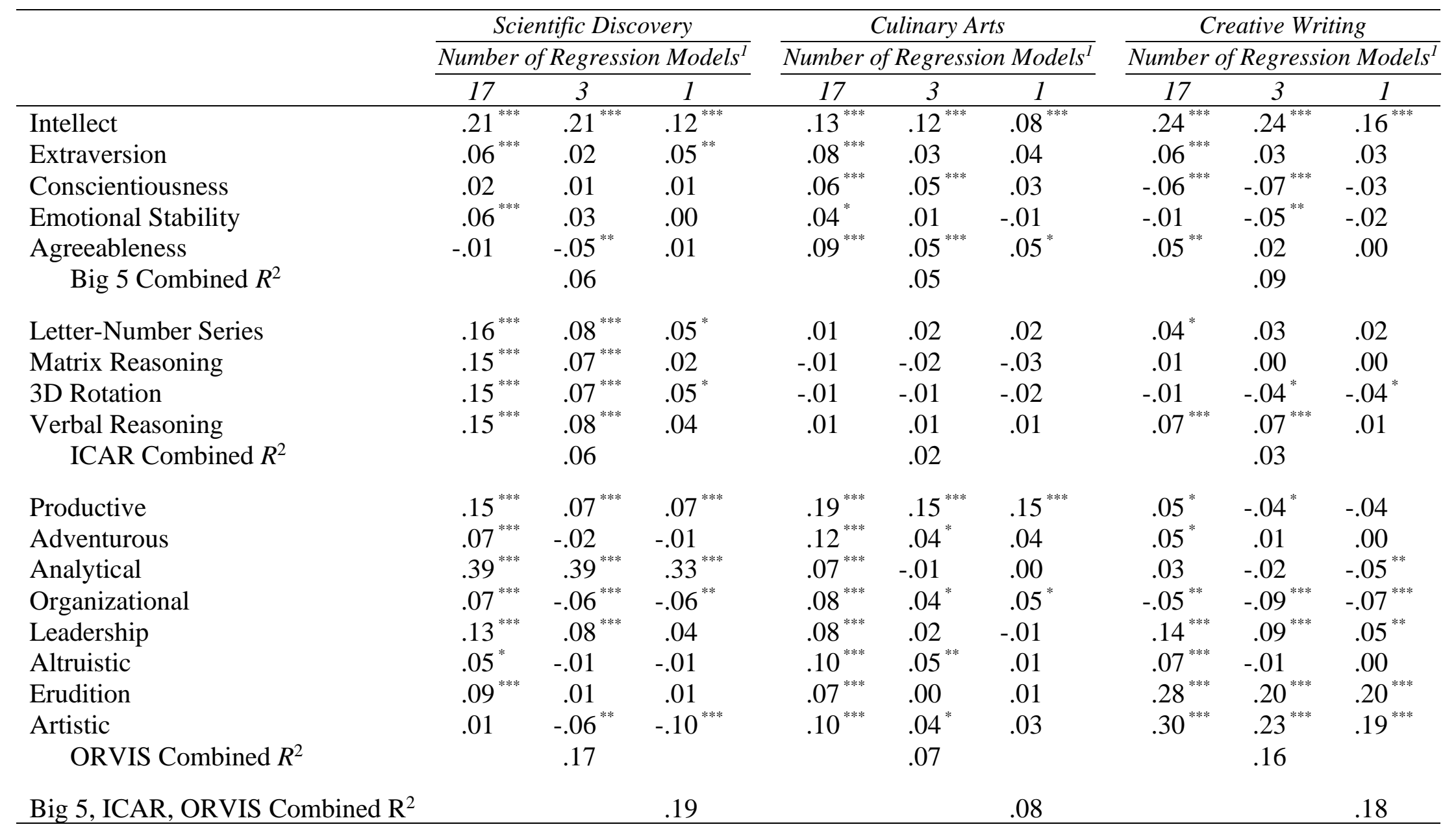

${ }^{1}$ Note: The values in the first creative domain column are the standardized regression coefficients from 17 separate regression analyses of the domain score predicted by each variable (e.g., Intellect), controlling for age and gender. The values in the second column are standardized regression coefficients and $R^{2}$ from 3 separate regressions analyses of the domain score predicted by each of the individual differences domains (Big Five, ICAR, ORVIS), controlling for age and gender. The values in the third creative domain column are the standardized regression coefficients and $R^{2}$ from a single regression analysis of the domain score predicted by age, gender, and all 17 of the factors combined.

${ }^{* * *} p<.001,{ }^{* *} p<.01,{ }^{*} p<.05$ 
Table 4 (continued). Regression Analyses of Individual Differences on CAQ Domain and Total Scores.

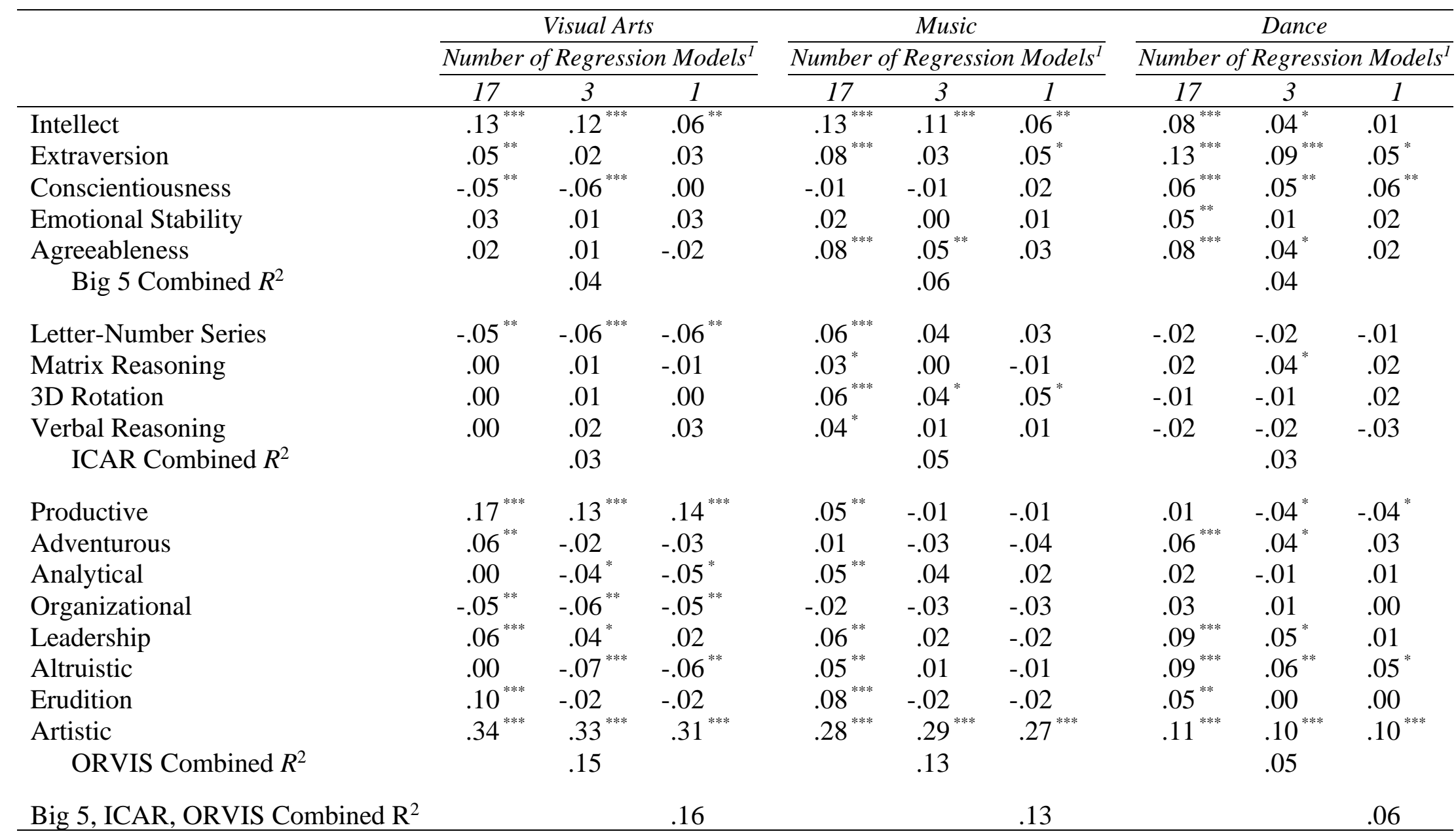

${ }^{1}$ Note: The values in the first creative domain column are the standardized regression coefficients from 17 separate regression analyses of the domain score predicted by each variable (e.g., Intellect), controlling for age and gender. The values in the second column are standardized regression coefficients and $R^{2}$ from 3 separate regressions analyses of the domain score predicted by each of the individual differences domains (Big Five, ICAR, ORVIS), controlling for age and gender. The values in the third creative domain column are the standardized regression coefficients and $R^{2}$ from a single regression analysis of the domain score predicted by age, gender, and all 17 of the factors combined.

${ }^{* * *} p<.001,{ }^{* *} p<.01,{ }^{*} p<.05$ 
Table 4 (continued). Regression Analyses of Individual Differences on CAQ Domain and Total Scores.

\begin{tabular}{|c|c|c|c|c|c|c|}
\hline & \multicolumn{3}{|c|}{ Theater/TV/Film } & \multicolumn{3}{|c|}{ Humor } \\
\hline & 17 & 3 & 1 & 17 & 3 & 1 \\
\hline Intellect & $.13^{* * *}$ & $.10^{* * *}$ & $.04^{*}$ & $.19^{* * *}$ & $.13^{* * * *}$ & $.10^{* * *}$ \\
\hline Extraversion & $.17^{* * *}$ & $.15^{* * *}$ & $.10^{* * *}$ & $.23^{* * *}$ & $.20^{* * *}$ & $.18^{* * *}$ \\
\hline Conscientiousness & -.02 & -.03 & .03 & -.02 & $-.05^{* *}$ & $-.05^{*}$ \\
\hline Emotional Stability & -.01 & $-.06^{* * *}$ & -.03 & $.05^{* *}$ & .00 & .01 \\
\hline Agreeableness & $.11^{* * *}$ & $.06^{* * *}$ & .04 & $.12^{* * *}$ & $.05^{* *}$ & .04 \\
\hline Big 5 Combined $R^{2}$ & & .05 & & & .10 & \\
\hline Letter-Number Series & .03 & .00 & .01 & -.01 & .01 & .01 \\
\hline Matrix Reasoning & .00 & -.03 & -.04 & -.03 & -.01 & -.01 \\
\hline 3D Rotation & $.05^{* *}$ & $.04^{*}$ & $.04^{*}$ & $-.06^{* * * *}$ & $-.07^{* * *}$ & $-.08^{* * *}$ \\
\hline Verbal Reasoning & $.06^{* * *}$ & $.06^{* * *}$ & $.06^{* * *}$ & .00 & .02 & .01 \\
\hline ICAR Combined $R^{2}$ & & .01 & & & .03 & \\
\hline Productive & .00 & $-.05^{*}$ & $-.05^{*}$ & $.05^{* *}$ & -.02 & .00 \\
\hline Adventurous & .01 & -.04 & -.03 & $.09^{* * *}$ & $.04^{*}$ & .01 \\
\hline Analytical & $-.06^{* *}$ & $-.09^{* * *}$ & $-.10^{* * *}$ & .02 & -.02 & -.01 \\
\hline Organizational & -.02 & $-.04^{*}$ & -.04 & .01 & -.04 & -.01 \\
\hline Leadership & $.17^{* * *}$ & $.16^{* * *}$ & $.11^{* * *}$ & $.16^{* * *}$ & $.12^{* * *}$ & .03 \\
\hline Altruistic & $.08^{* * * *}$ & .02 & -.01 & $.10^{* * * *}$ & $.04^{*}$ & .00 \\
\hline Erudition & $.12^{* * *}$ & .03 & $.04^{*}$ & $.10^{* * *}$ & .02 & $.05^{*}$ \\
\hline Artistic & $.27^{* * *}$ & $.25^{* * *}$ & $.24^{* * *}$ & $.19^{* * *}$ & $.16^{* * *}$ & $.12^{* * *}$ \\
\hline ORVIS Combined $R^{2}$ & & .11 & & & .08 & \\
\hline
\end{tabular}

Big 5, ICAR, ORVIS Combined $\mathrm{R}^{2}$ .13 .13

${ }^{1}$ Note: The values in the first creative domain column are the standardized regression coefficients from 17 separate regression analyses of the domain score predicted by each variable (e.g., Intellect), controlling for age and gender. The values in the second column are standardized regression coefficients and $R^{2}$ from 3 separate regressions analyses of the domain score predicted by each of the individual differences domains (Big Five, ICAR, ORVIS), controlling for age and gender. The values in the third creative domain column are the standardized regression coefficients and $R^{2}$ from a single regression analysis of the domain score predicted by age, gender, and all 17 of the factors combined.

${ }^{* * *} p<.001,{ }^{* *} p<.01,{ }^{*} p<.05$ 


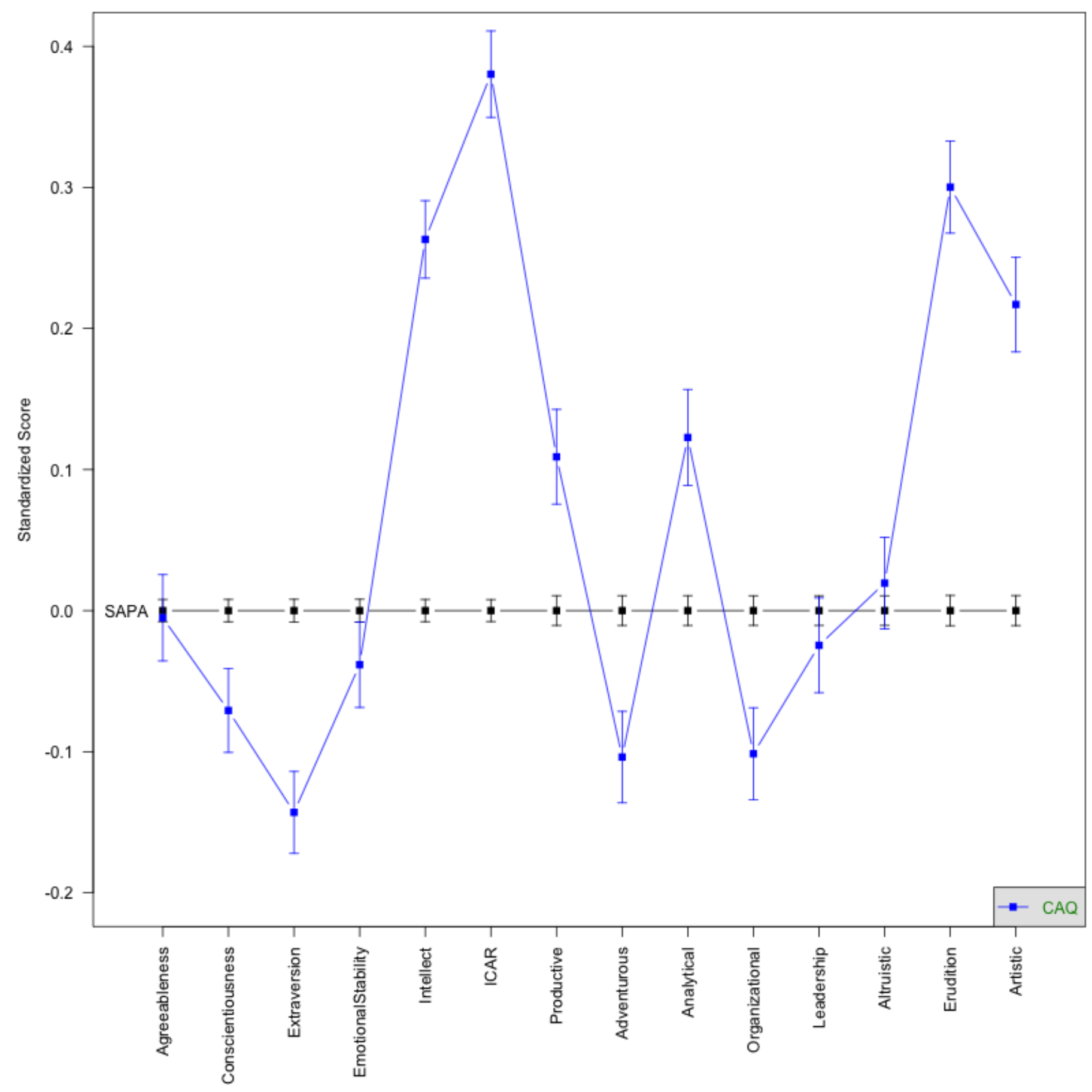

Figure 1. Mean standardized scores and 95\% confidence intervals for baseline non-responders (SAPA) and CAQ respondents on the Big Five scales, the International Cognitive Ability Resource scales, and the Oregon Vocational Interest Scales. 


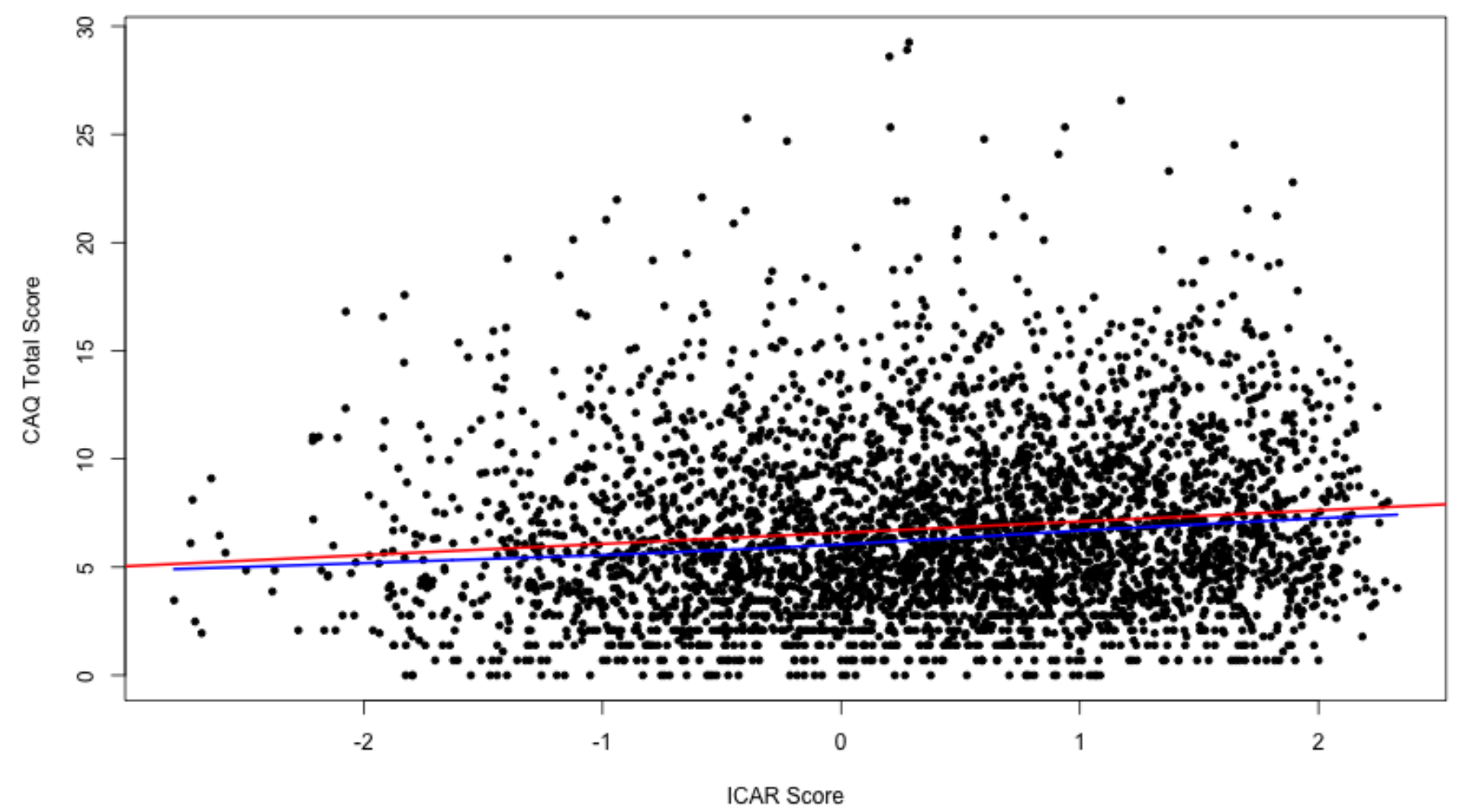

Figure 2. Scatterplot of Creative Achievement scores by standardized Cognitive Ability scores with regression line (red) and Loess line of best fit (blue). 


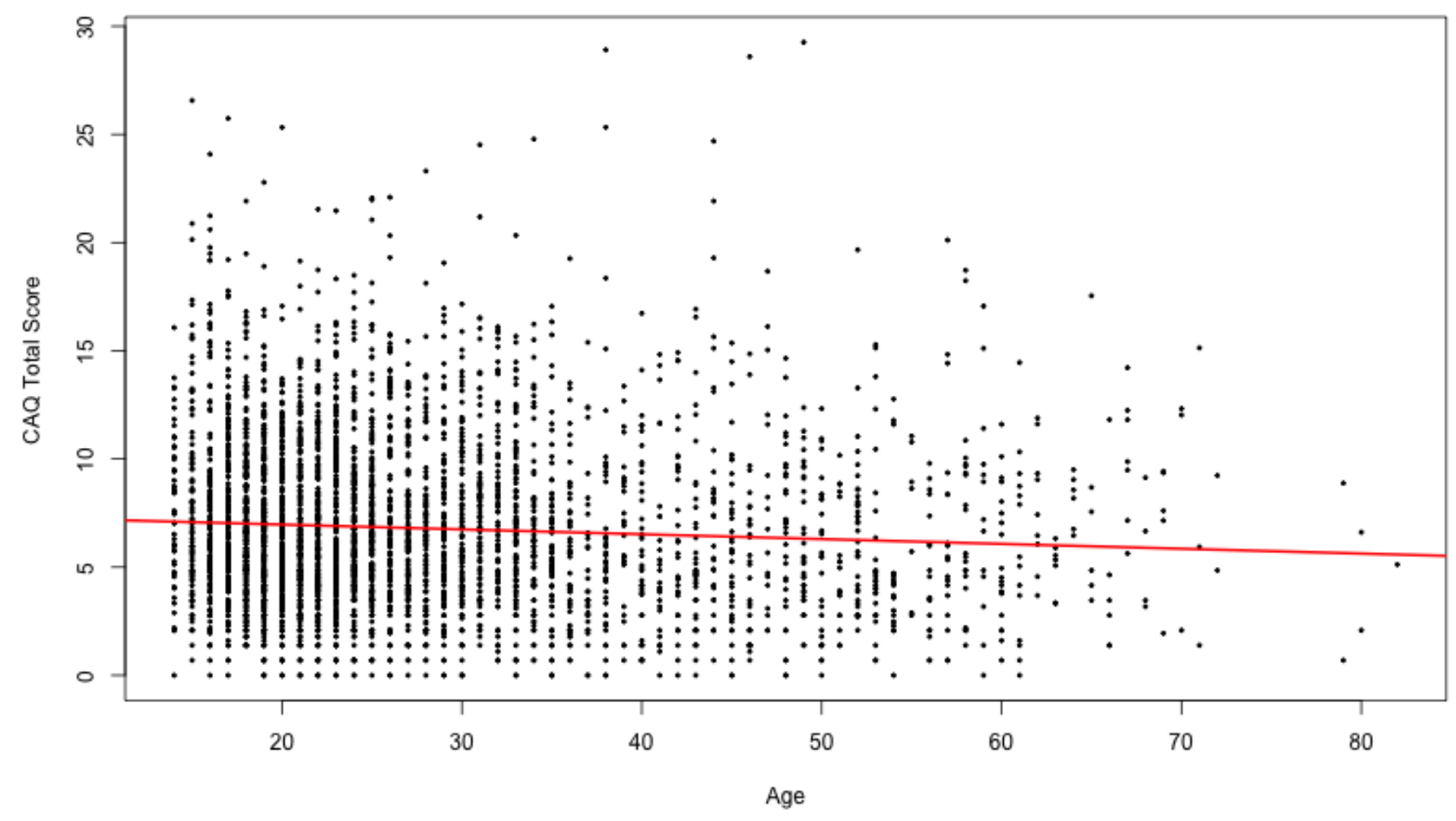

Figure 3. Scatterplot of Creative Achievement scores (all questions) by age with the line of best fit. 


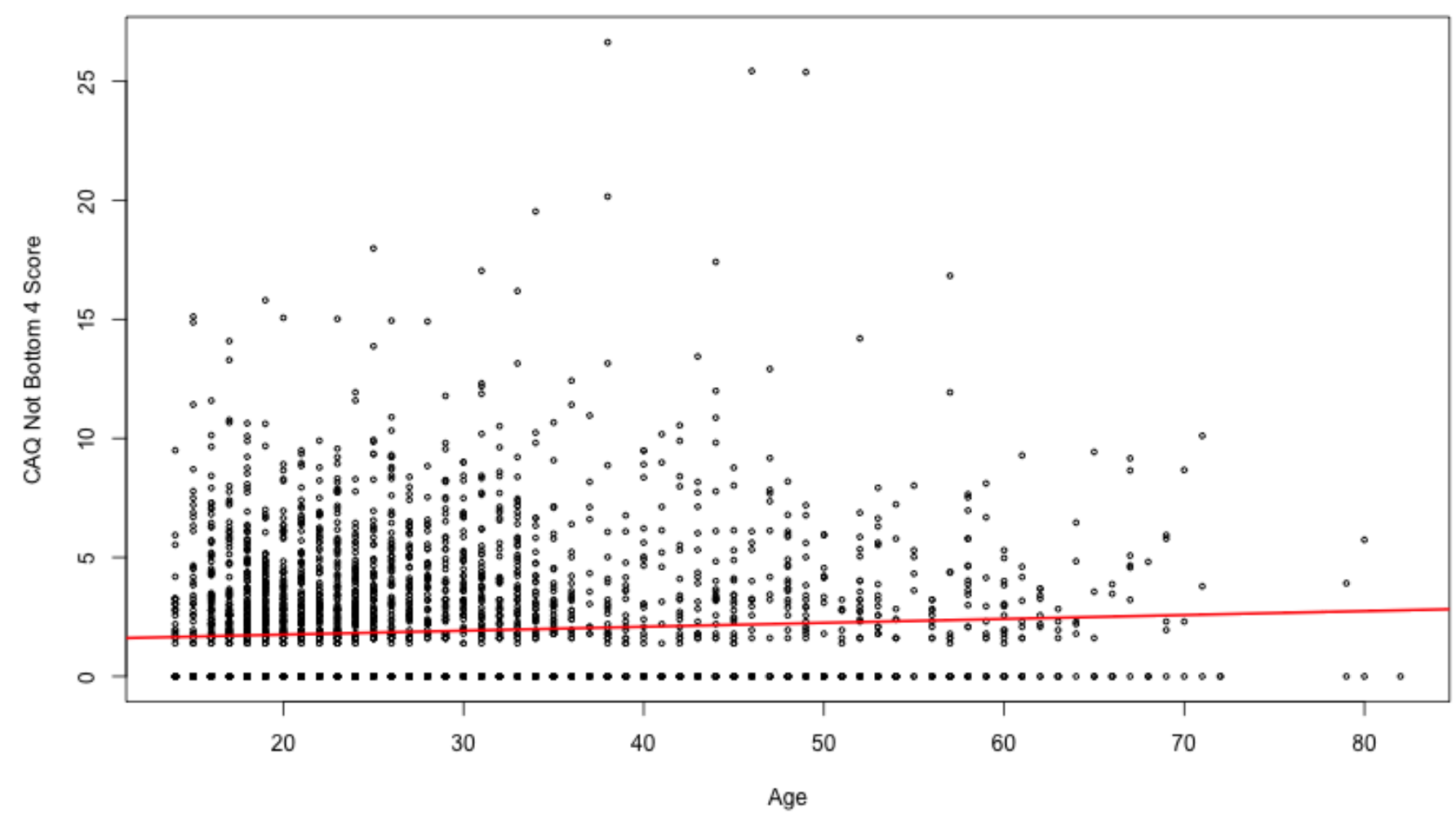

Figure 4. Scatterplot of Creative Achievement scores (excluding the bottom 4 questions) by age with the line of best fit. 


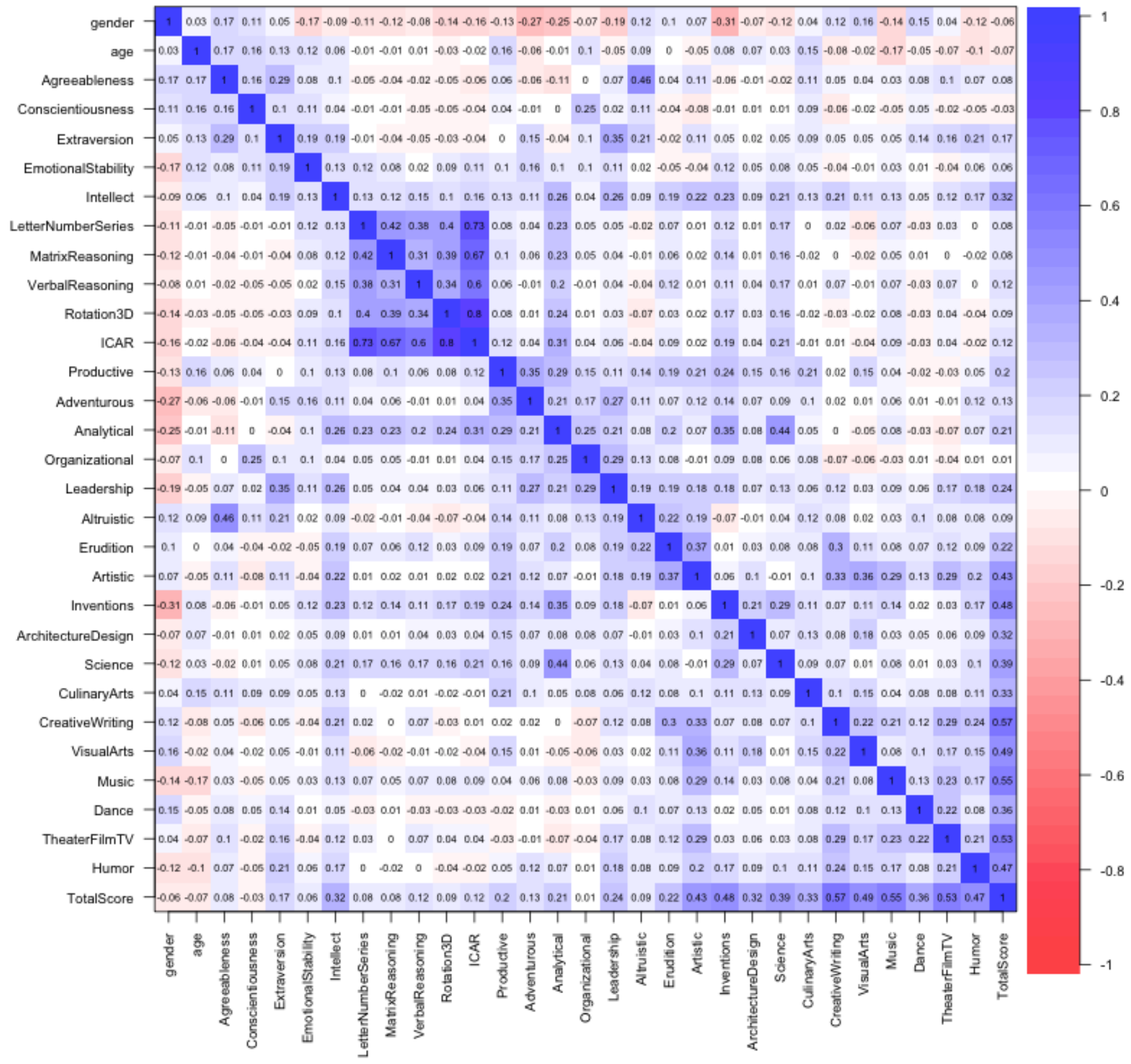

Figure 5. Zero-order correlation matrix of gender, age, Big Five, ICAR, vocational interest, and

\section{CAQ scores.}




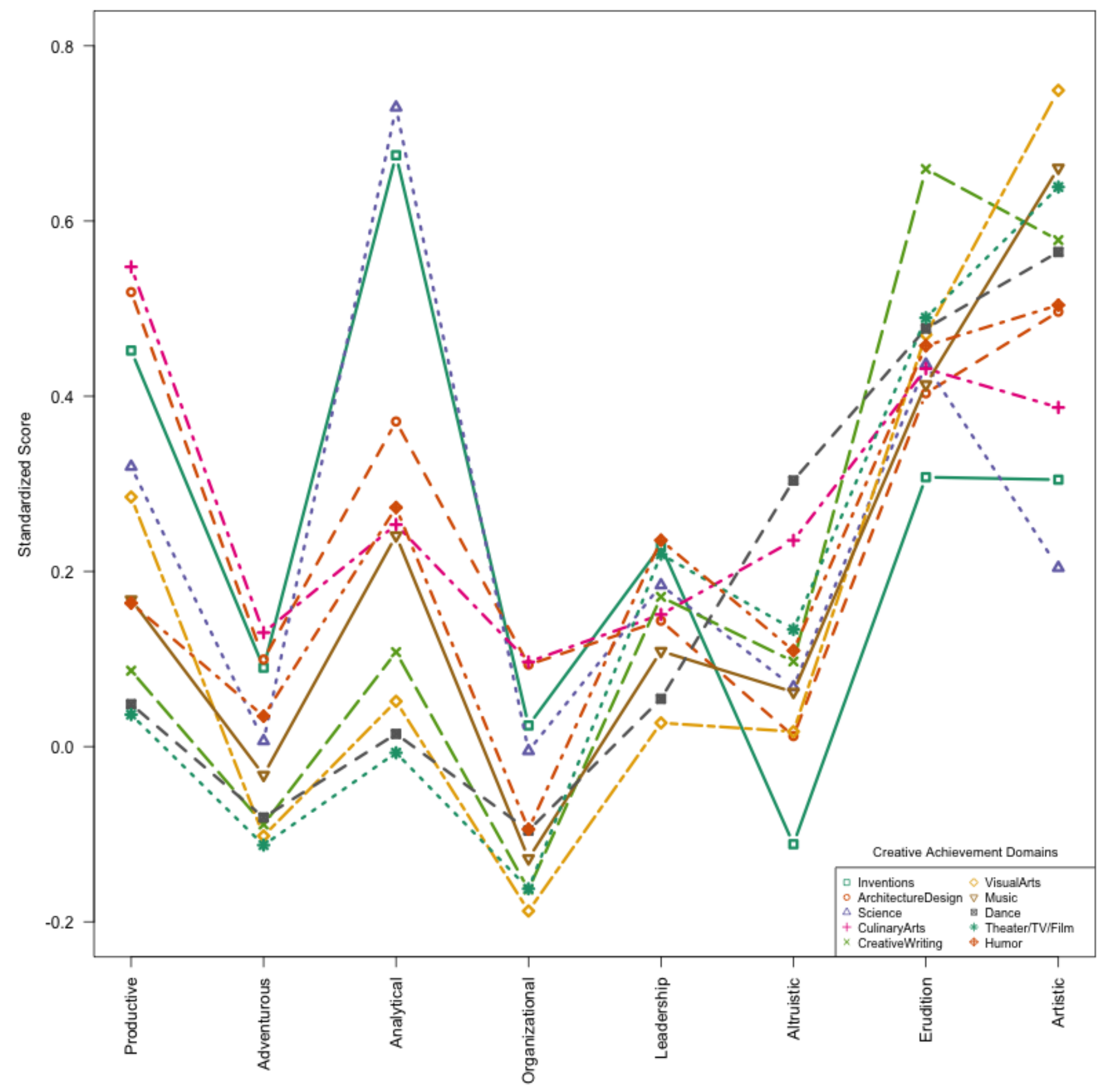

Figure 6. Mean vocational interest scores of top 25\% scorers in each creative domain. 


\section{Appendix}

This is a revised version of the Creative Achievement Questionnaire (Carson, Peterson, \& Higgins (2005) used by Zabelina, Zaonegina, Revelle, \& Condon.

\section{Inventions \& Innovations}

1. I don't have much talent in this area.

2. I regularly find novel uses for household objects.

3. I have sketched out an invention and worked on its design flaws.

4. I have created original software for a computer.

$\square \quad 1$ time

$$
2 \text { times }
$$

3-5 times

6-9 times

10-19 times

$20+$ times

5. I have built a prototype of one of my designed inventions.

$\begin{array}{ll}\square & 1 \text { time } \\ \square & 2 \text { times } \\ \square & 3-5 \text { times } \\ \square & 6-9 \text { times } \\ \square & 10-19 \text { times } \\ \square & 20+\text { times }\end{array}$

6. I have received orders for one of my inventions.

$\begin{array}{ll}\square & 1 \text { time } \\ \square & 2 \text { times } \\ \square & 3-5 \text { times } \\ \square & 6-9 \text { times } \\ \square & 10-19 \text { times } \\ \square & 20+\text { times }\end{array}$

7. I have sought an investment for one of my inventions.

$\square \quad 1$ time

$\square \quad 2$ times

$\square \quad 3-5$ times

6-9 times

10-19 times

$20+$ times

8. I have received a patent for one of my inventions.

$\square \quad 1$ time

$$
2 \text { times }
$$

3-5 times

6-9 times

10-19 times

$20+$ times

9. I have sold the rights to one or more of my inventions.

$\square \quad 1$ time

$$
2 \text { times }
$$

3-5 times

6-9 times

10-19 times 
$20+$ times

10. I own or operate a business based on one of my inventions (or have in the past).

\section{Music}

1. I don't have much talent in this area.

2. I play one or more musical instruments proficiently.

3. I have played with a recognized orchestra or band.

$\begin{array}{ll}\square & 1 \text { time } \\ \square & 2 \text { times } \\ \square & 3-5 \text { times } \\ \square & \text { 6-9 times } \\ \square & 10-19 \text { times } \\ \square & 20+\text { times }\end{array}$

4. I have composed an original piece of music.

$\square \quad 1$ time

2 times

3-5 times

6-9 times

10-19 times

$20+$ times

5. My musical talent has been critiqued in a local publication.

\section{$\square \quad 1$ time \\ 2 times \\ 3-5 times \\ 6-9 times \\ 10-19 times \\ $20+$ times}

6. My composition has been recorded.

$\begin{array}{ll}\square & 1 \text { time } \\ \square & 2 \text { times } \\ \square & 3-5 \text { times } \\ \square & \text { 6-9 times } \\ \square & 10-19 \text { times } \\ \square & 20+\text { times }\end{array}$

7. Recordings of my composition have been sold publicly.

$\begin{array}{ll}\square & 1 \text { time } \\ \square & 2 \text { times } \\ \square & \text { 3-5 times } \\ \square & \text { 6-9 times } \\ \square & 10-19 \text { times } \\ \square & 20+\text { times }\end{array}$

8. My compositions have been critiqued in a national publication.

$\begin{array}{ll}\square & 1 \text { time } \\ \square & 2 \text { times } \\ \square & 3-5 \text { times } \\ \square & \text { 6-9 times } \\ \square & 10-19 \text { times } \\ \square & 20+\text { times }\end{array}$

\section{Theater/TV/Film}


1. I don't have much talent in this area.

2. I have performed in theater, film, or TV.

$\square \quad 1$ time

2 times

3-5 times

6-9 times

10-19 times

$20+$ times

3. My acting has been recognized in a local publication.

$\begin{array}{ll}\square & 1 \text { time } \\ \square & 2 \text { times } \\ \square & 3-5 \text { times } \\ \square & \text { 6-9 times } \\ \square & 10-19 \text { times } \\ \square \quad & 20+\text { times }\end{array}$

4. I have directed or produced a theater, film or TV production.

$\begin{array}{ll}\square & 1 \text { time } \\ \square & 2 \text { times } \\ \square & 3-5 \text { times } \\ \square & 6-9 \text { times } \\ \square \quad & 10-19 \text { times } \\ \square \quad & 20+\text { times }\end{array}$

5. I have won an award or prize for acting.

$\begin{array}{ll}\square & 1 \text { time } \\ \square & 2 \text { times } \\ \square & 3-5 \text { times } \\ \square & 6-9 \text { times } \\ \square & 10-19 \text { times } \\ \square & 20+\text { times }\end{array}$

6. I have been paid to act in theater, film or TV.

$\square \quad 1$ time

2 times

3-5 times

6-9 times

10-19 times

$20+$ times

7. I have been paid to direct a theater, film or TV production.

$\begin{array}{ll}\square & 1 \text { time } \\ \square & 2 \text { times } \\ \square & 3-5 \text { times } \\ \square & 6-9 \text { times } \\ \square \quad & 10-19 \text { times } \\ \square \quad & 20+\text { times }\end{array}$

8. My theatrical work has been recognized in a national publication.

$\square \quad 1$ time

2 times

3-5 times

6-9 times

10-19 times

$20+$ times 


\section{Scientific Discovery}

1. I don't have much talent in this area.

2. I often think about ways that scientific problems could be solved.

3. I have won a prize at a science fair or other local competition.

1 time

2 times

3-5 times

6-9 times

10-19 times

$20+$ times

4. I have received a scholarship based on my work in science or medicine.

1 time

2 times

3-5 times

6-9 times

10-19 times

$20+$ times

5. I have been an author or coauthor of a study published in a scientific journal.

1 time

2 times

3-5 times

6-9 times

$10-19$ times

$20+$ times

6. I have received a grant to pursue my work in science or medicine.

$\square \quad 1$ time

2 times

3-5 times

6-9 times

10-19 times

$20+$ times

7. I have won an award for my achievements in science or medicine.

$\begin{array}{ll}\square & 1 \text { time } \\ \square & 2 \text { times } \\ \square & 3-5 \text { times } \\ \square & \text { 6-9 times } \\ \square & 10-19 \text { times } \\ \square & 20+\text { times }\end{array}$

8. My work has been cited by other scientists in books or articles.

$\square \quad 1$ time

2 times

3-5 times

6-9 times

10-19 times

$20+$ times

\section{Creative Writing}

1. I don't have much talent in this area. 
2. I have written an original short work (poem or short story).

$\square \quad 1$ time

2 times

3-5 times

6-9 times

$10-19$ times

$20+$ times

3. My work has won an award or prize.

$\square \quad 1$ time

2 times

3-5 times

6-9 times

10-19 times

20+ times

4. I have written an original long work (epic, novel, or play).

$\square \quad 1$ time

2 times

3-5 times

6-9 times

10-19 times

$20+$ times

5. I have sold my work to a publisher.

$\square \quad 1$ time

2 times

3-5 times

6-9 times

10-19 times

$20+$ times

6. My work has been printed and sold publicly.

$\square \quad 1$ time

2 times

3-5 times

6-9 times

10-19 times

$20+$ times

7. My work has been reviewed in local publications.

$\square \quad 1$ time

2 times

3-5 times

6-9 times

10-19 times

$20+$ times

8. My work has been reviewed in national publications.

$\square \quad 1$ time

2 times

3-5 times

6-9 times

10-19 times

$20+$ times 


\section{Dance}

1. I don't have much talent in this area.

2. I have danced with a recognized dance company.

3. I have choreographed an original dance number.

1 time

2 times

3-5 times

6-9 times

$10-19$ times

$20+$ times

4. My choreography has been performed publicly.

1 time

2 times

3-5 times

6-9 times

10-19 times

$20+$ times

5. My dance abilities have been critiqued in a local publication.

$\begin{array}{ll}\square & 1 \text { time } \\ \square & 2 \text { times } \\ \square & 3-5 \text { times } \\ \square & \text { 6-9 times } \\ \square & 10-19 \text { times } \\ \square & 20+\text { times }\end{array}$

6. I have choreographed dance professionally.

$\square \quad 1$ time

2 times

3-5 times

6-9 times

10-19 times

$20+$ times

7. My choreography has been recognized by a local publication.

$\begin{array}{ll}\square & 1 \text { time } \\ \square & 2 \text { times } \\ \square & 3-5 \text { times } \\ \square & \text { 6-9 times } \\ \square & 10-19 \text { times } \\ \square & 20+\text { times }\end{array}$

8. My choreography has been recognized by a national publication.

$\begin{array}{ll}\square & 1 \text { time } \\ \square & 2 \text { times } \\ \square & 3-5 \text { times } \\ \square & \text { 6-9 times } \\ \square & 10-19 \text { times } \\ \square & 20+\text { times }\end{array}$

\section{Culinary Arts}

1. I don't have much talent in this area.

2. I often experiment with recipes.

3. My recipes have been used in restaurants or other public venues. 
4. I have been employed as a cook or professional chef.

5. I have been asked to prepare food for celebrities or dignitaries.

\begin{tabular}{ll}
$\square$ & 1 time \\
\hline$\square$ & 2 times \\
$\square$ & $3-5$ times \\
$\square$ & 6-9 times \\
$\square \quad$ & $10-19$ times \\
$\square \quad$ & $20+$ times
\end{tabular}

6. My recipes have won a prize or award.

$\square \quad 1$ time

$\square \quad 2$ times

3-5 times

6-9 times

10-19 times

$20+$ times

7. I have received a degree in culinary arts.

$\square \quad 1$ time

2 times

3-5 times

6-9 times

10-19 times

$20+$ times

8. My recipes have been published in a book or magazine.

$\square \quad 1$ time

$\square \quad 2$ times

$\square \quad 3-5$ times

$\square \quad 6-9$ times

$\square \quad 10-19$ times

$20+$ times

\section{Visual Arts (painting, sculpture, photography)}

1. I don't have much talent in this area.

2. People have commented on my talent in this area.

3. I have won a prize or prizes at a juried art show.

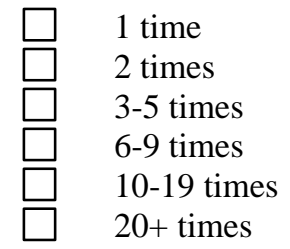

4. I have had a showing of my work(s) in a gallery.

$\begin{array}{ll}\square & 1 \text { time } \\ \square & 2 \text { times } \\ \square & 3-5 \text { times } \\ \square & \text { 6-9 times } \\ \square & \text { 10-19 times } \\ \square \quad & 20+\text { times }\end{array}$


5. I have sold a piece of my work.

$\square \quad 1$ time

2 times

3-5 times

6-9 times

10-19 times

$20+$ times

6. My work has been critiqued in a local publication.

$\square \quad 1$ time

2 times

3-5 times

6-9 times

10-19 times

$20+$ times

7. My work has been critiqued in national publications.

$\square \quad 1$ time

2 times

3-5 times

6-9 times

10-19 times

$20+$ times

\section{Humor}

1. I don't have much talent in this area.

2. People have often commented on my original sense of humor.

3. I have created jokes that are now regularly repeated by others.

4. I have written jokes for other people.

$\square \quad 1$ time

2 times

3-5 times

6-9 times

10-19 times

$20+$ times

5. I have written a joke or cartoon that has been published.

$\square \quad 1$ time

2 times

3-5 times

6-9 times

10-19 times

$20+$ times

6. I have worked as a professional comedian.

$\square \quad 1$ time

2 times

3-5 times

6-9 times

10-19 times

$20+$ times 
7. I have worked as a professional comedy writer.

$\square \quad 1$ time

$\square \quad 2$ times

$\square \quad 3-5$ times

$\square \quad 6-9$ times

$10-19$ times

$20+$ times

8. My humor has been recognized in a national publication.

$\square \quad 1$ time

$\square \quad 2$ times

$\square \quad 3-5$ times

$\square \quad 6-9$ times

$\square \quad 10-19$ times

$20+$ times

\section{Architectural Design}

1. I don't have much talent in this area.

2. I have designed an original structure.

$\square \quad 1$ time

2 times

3-5 times

$\square \quad 6-9$ times

$\square \quad 10-19$ times

$20+$ times

3. A structure designed by me has been constructed.

$\square \quad 1$ time

$\square \quad 2$ times

$\square \quad 3-5$ times

$\square \quad 6-9$ times

10-19 times

$20+$ times

4. I have sold an original architectural design.
$\square \quad 1$ time
2 times
3-5 times
$\square \quad 6-9$ times
$\square \quad$ 10-19 times

5. A structure that I have designed and sold has been built professionally.

$\square \quad 1$ time

$\square \quad 2$ times

$\square \quad 3-5$ times

$\square \quad 6-9$ times

$\square \quad 10-19$ times

$20+$ times 
6. My architectural design has won an award or awards.

$\square \quad 1$ time

$\square \quad 2$ times

$\square \quad 3-5$ times

$\square \quad 6-9$ times

$\square \quad$ 10-19 times

7. My architectural design has been recognized in a local publication.

$\square \quad 1$ time

$\square \quad 2$ times

$\square \quad 3-5$ times

$\square \quad 6-9$ times

$\square \quad 10-19$ times

$20+$ times

8. My architectural design has been recognized in a national publication.

$\square \quad 1$ time

$\square \quad 2$ times

$\square \quad 3-5$ times

$\square \quad 6-9$ times

$\square \quad$ 10-19 times

$\square \quad 20+$ times 


\section{Scoring Instructions}

Each domain is scored independently. A checkmark in the first item for each domain is scored as "0". This item is maintained to distinguish participants who do not respond to any items in a domain from those who do not have any achievements in that domain. If the participant checks only the first box for a given domain, their score for the entire domain is " 0 ". If the participant checks the first box AND one or more of the subsequent boxes in that domain, the domain is scored as if they had not checked the first box. If the participant does not check the first box or any other items, their score for the domain should be treated as "NA".

After the first item in each domain, items with frequency ranges for the response choices are scored as " 0 " if none of the boxes are checked or from 1 (for "1 time") to 6 (for " $20+$ times"). Items without frequency ranges are scored as " 1 " if checked; otherwise they are scored as " 0 ".

These raw scores are then multiplied by domain specific weights. The weights for each domain are given in the table below. For example, a participant who had the following raw scores for the Inventions and Innovations domain:

$0,1,1,0,3,3,2,1,1,0$

would have a weighted domain score of:

$(0 * 1)+(1 * 1)+(1 * 2)+(0 * 3)+(3 * 3)+(3 * 4)+(2 * 5)+(1 * 6)+(1 * 6)+(0 * 7)=46$

A total score across all domains can be calculated by using the average of the standardized scores (" $\mathrm{z}$ scores) for each domain.

Scoring Weights by Domain

\begin{tabular}{|l|c|c|c|c|c|c|c|c|c|c|}
\hline \multicolumn{1}{|c|}{ Domain } & Item & Item & Item & Item & Item & Item & Item & Item & Item & Item \\
$\mathbf{9}$ & $\mathbf{1}$ & $\mathbf{2}$ & $\mathbf{4}$ & $\mathbf{5}$ & $\mathbf{6}$ & $\mathbf{7}$ & $\mathbf{8}$ & $\mathbf{9}$ & $\mathbf{1 0}$ \\
\hline Inventions and Innovations & 1 & 1 & 2 & 3 & 3 & 4 & 5 & 6 & 6 & 7 \\
Music & 1 & 1 & 2 & 3 & 4 & 5 & 6 & 7 & NA & NA \\
Theater/TV/Film & 1 & 1 & 2 & 3 & 4 & 5 & 6 & 7 & NA & NA \\
Scientific Discovery & 1 & 1 & 2 & 3 & 4 & 5 & 6 & 7 & NA & NA \\
Creative Writing & 1 & 1 & 2 & 3 & 4 & 5 & 6 & 7 & NA & NA \\
Dance & 1 & 1 & 2 & 3 & 4 & 5 & 6 & 7 & NA & NA \\
Culinary Arts & 1 & 1 & 2 & 3 & 6 & 7 & 4 & 5 & NA & NA \\
Visual Arts & 1 & 1 & 2 & 3 & 4 & 5 & 6 & NA & NA & NA \\
Humor & 1 & 1 & 2 & 3 & 4 & 5 & 6 & 7 & NA & NA \\
Architectural Design & 1 & 1 & 2 & 3 & 4 & 5 & 6 & 7 & NA & NA \\
\hline
\end{tabular}

